IZA DP No. 6601

Does Promoting School Attendance Reduce Child Labour? Evidence from Burkina Faso's BRIGHT Project

Jacobus de Hoop

Furio C. Rosati

May 2012 


\title{
Does Promoting School Attendance Reduce Child Labour? Evidence from Burkina Faso's BRIGHT Project
}

\author{
Jacobus de Hoop \\ Understanding Children's Work \\ Furio C. Rosati \\ Understanding Children's Work \\ and IZA \\ Discussion Paper No. 6601 \\ May 2012 \\ IZA \\ P.O. Box 7240 \\ 53072 Bonn \\ Germany \\ Phone: +49-228-3894-0 \\ Fax: +49-228-3894-180 \\ E-mail: iza@iza.org
}

Any opinions expressed here are those of the author(s) and not those of IZA. Research published in this series may include views on policy, but the institute itself takes no institutional policy positions.

The Institute for the Study of Labor (IZA) in Bonn is a local and virtual international research center and a place of communication between science, politics and business. IZA is an independent nonprofit organization supported by Deutsche Post Foundation. The center is associated with the University of Bonn and offers a stimulating research environment through its international network, workshops and conferences, data service, project support, research visits and doctoral program. IZA engages in (i) original and internationally competitive research in all fields of labor economics, (ii) development of policy concepts, and (iii) dissemination of research results and concepts to the interested public.

IZA Discussion Papers often represent preliminary work and are circulated to encourage discussion. Citation of such a paper should account for its provisional character. A revised version may be available directly from the author. 


\title{
ABSTRACT
}

\section{Does Promoting School Attendance Reduce Child Labour? Evidence from Burkina Faso's BRIGHT Project}

\begin{abstract}
Using data from BRIGHT, an integrated program that aims to improve school participation in rural communities in Burkina Faso, we investigate the impact of school subsidies and increased access to education on child work. Regression discontinuity estimates demonstrate that, while BRIGHT substantially improved school participation, it increased children's participation in economic activities and chores. This combination of increased school participation and work can be explained by the introduction of a simple non convexity in the standard model of altruistic utility maximizing households. If education programs are implemented to achieve a combination of increased school participation and a reduction in child work, they may either have to be combined with different interventions that effectively reduce child work or they may have to be tuned more carefully to the incentives and constraints the child laborer faces.
\end{abstract}

JEL Classification: $\quad$ I25, J22, J24, O12, 055

Keywords: Burkina Faso, child labour, regression discontinuity, school participation

Corresponding author:

Furio C. Rosati

Understanding Children's Work (UCW)

c/o CEIS, University of Rome "Tor Vergata"

Via Columbia 2

00133 Rome

Italy

E-mail: frosati@ucw-project.org 


\section{Introduction $^{1}$}

High costs of education and limited access to schools are often seen as important determinants of child labour. Reductions in the cost of education and increased access to schools are therefore advocated as an instrument to reduce the incidence of child labour. However, the impact of such interventions on child labour is not unambiguous from a theoretical point of view (Cigno and Rosati, 2005; Edmonds, 2007). ${ }^{2}$ In fact, policies aimed at promoting school participation risk increasing child labour if they are not carefully tailored to the incentives and constraints faced by children in developing countries. Empirical evidence on this matter therefore has important policy implications.

In this paper we look at the impact of Burkina Faso's BRIGHT program on several dimensions of child work. BRIGHT implemented a package of education interventions in 132 rural villages consisting of two main components: the construction of a primary school and the provision of direct incentives for school participation in the form of school meals for all pupils and take-home rations for female pupils. ${ }^{3}$ Evidence on the impact of interventions that, like the BRIGHT program, provide in-kind subsidies for school participation and reduce the cost of traveling to school on child work is scarce and does not always exploit unambiguously exogenous variation in treatment status.

Two previous papers evaluate the impact of the provision of food for education programs on child labour. Ravaillon and Wodon (2000) use (non-

\footnotetext{
${ }^{1}$ We thank Marco Manacorda for valuable comments. The findings, interpretations, and conclusions expressed in this paper are entirely those of the authors. They do not necessarily represent the views of UCW or its partner organizations: the International Labour Organization, UNICEF, and the World Bank. Funding for this project was provided by the United States Department of Labor. This document does not necessarily reflect the views or policies of the United States Department of Labor, nor does mention of trade names, commercial products, or organizations imply endorsement by the United States Government.

${ }^{2}$ The ambiguity stems mainly from the fact that school attendance and work are not mutually exclusive activities, as children can adjust leisure following a change in the relative price of education or changes in the income available to the household.

${ }^{3}$ In addition, the program implemented a range of advocacy measures.
} 
random) program placement as an instrument to identify the effect of the provision of monthly food rations in Bangladesh. They find that the provision of school meals substantially increases school attendance, but results in a markedly smaller decrease in child work: children appear to be substituting leisure with schooling, only marginally reducing the time devoted to work. Kazianga et al. (2008) use a randomized controlled trial to evaluate the impact of school meals and take-home rations in Burkina Faso. They find mixed effects of these interventions on school participation and child work, primarily among girls. Girls' school enrollment increases as a result of the interventions, but their average attendance deteriorates. Moreover girls alter the allocation of labour away from productive activities toward domestic activities which, the authors argue, children can combine more easily with school activities.

To our knowledge, Kondylis and Manacorda (2012) is the most recent paper to examine the role of school proximity. The authors use micro data from Tanzania to investigate the relationship between distance to school and work and school participation. The estimates do not exploit an exogenous instrument to identify the causal effect of distance to school on work and school participation. Instead, the estimations control for observed socioeconomic characteristics of households and distance to other facilities which, the authors argue, helps correct for non-random spatial distribution of households within the village. Their results suggest that school proximity leads to a rise in school attendance, but not to a noticeable reduction in child labour.

The BRIGHT project offers a particularly interesting opportunity to provide additional evidence on the impact of this type of education interventions on child labour. First, BRIGHT is well situated to bring about changes in school participation and child labour, as school participation rates in Burkina Faso rank among the lowest in the world and children are widely engaged in economic activities and household chores (henceforth we use the term work to refer to the combination of children's economic activities and 
chores). Second, extensive household, child, and school surveys administered as part of the program allow us to provide detailed evidence on the interaction between child labour and school participation. Third, the setup of the BRIGHT program provides a strong quasi-experimental identification mechanism.

This identification mechanism exploits the fact that BRIGHT was allocated on the basis of an index that ranked villages in order of their potential to improve school attendance and education outcomes. A total of 293 rural villages from 49 departments subscribed for participation in the BRIGHT program. Within each department, the subscribing villages were ranked based on this index and those in the top half of the ranking were selected into the program. Following Levy et al. (2009), we exploit this assignment procedure in a regression discontinuity framework to estimate the causal effect of the BRIGHT program. A limitation that should be noted at the outset is that this estimation procedure does not allow us to distinguish the marginal impact of the separate components of the BRIGHT program (i.e. the construction of schools and the provision of in-kind incentives).

In accordance with Levy et al. (2009), we find that BRIGHT had a strong impact on school participation. Regression discontinuity estimates suggest that school enrollment exhibits a discontinuity of roughly 13 percentage points in marginal BRIGHT villages. More surprisingly, despite this marked increase in school participation, we observe no decrease in the prevalence of child work in the marginal BRIGHT villages. If anything, our estimates indicate that children's participation in work increased as a result of the BRIGHT education interventions.

We show that this pattern of changes in schooling and child labour status is consistent with the predictions of a simple altruistic household utility maximization model. Broadly speaking, the model indicates that some of the children who were not in school before the intervention will enroll and that the children who were already in school will remain enrolled. There is no such clear theoretical prediction for the change in child work. Among children who 
were already in school, the change in the prevalence of child work is ambiguous. The same holds among children who begin to attend school as a consequence of the program. Finally, if there is some degree of income pooling, we can expect spillover income effects from the take-home rations provided to enrolled girls on male siblings.

A more articulate picture emerges when we decompose the overall impact of BRIGHT to account for these potential spillover effects. There is evidence of substantially increased school participation for girls, boys without female siblings, and boys with female siblings (who potentially benefit from spillover effects). However, changes in work participation are not the same within these subgroups. Girls appear to have increased their school participation without altering their involvement in work. Boys, particularly those without female siblings, do appear to have increased their participation in work.

When we take a closer look at children's involvement in work, we find that the increase in work participation among boys primarily takes place within the household. We find no discontinuities in the types of activities conducted by children nor do we find discontinuities in remunerated activities. Moreover, although here the information is more limited, we find no evidence that the intensive margin of child work changed in marginal BRIGHT villages.

Importantly, we also find little evidence that working while attending school has a detrimental effect on school participation. Children attend school regularly when they are enrolled, as suggested by self-reported attendance, teacher reported attendance, and information obtained during surprise school visits. Moreover, we find that children in marginal BRIGHT villages exhibit improvements in performance on a mathematics and French language test of roughly 2 to .4 standard deviations. Improvements in learning outcomes are comparable among children who are in school only and those who combine school attendance with work. 
Together, the presented results suggest that in a low income country like Burkina Faso promoting school enrollment does not necessarily reduce children's involvement in work. On the contrary, it might raise participation in work for some groups of children. However, there is no evidence that the increase in child work hampers school attendance or reduces learning in school.

The remainder of this paper is structured as follows. Section 2 develops the model that guides the interpretation of the results in the paper. Section 3 discusses the setting, the design of the BRIGHT project, and the data we use in this paper. Section 4 provides a description of the estimation procedures and presents the results and section 5 concludes.

\section{Theoretical Outline}

In this section we develop a simple model that provides basic insights into the relationship between households' schooling and work decisions on the one hand and the monetary and time costs of education on the other. We consider a unitary household decision model with parents maximizing a utility function defined over household consumption, children's leisure, and children's education. This very simple model captures the characteristics of an altruistic overlapping generation model that are essential for the development of our analysis.

We assume that the number of children is predetermined and equal to one (i.e. we treat fertility as exogenous) and that adult labour supply is fixed. Relaxing these assumptions will not change our main results. ${ }^{4}$ More critically, we assume that households do not have access to capital markets: if they did, investment in human capital would be separable from consumption decisions. As this paper concerns households living in rural Burkina Faso, the hypothesis of an imperfect credit market looks reasonable. Finally, we assume that school attendance requires a fixed amount of time, i.e. if the parents decide to send

\footnotetext{
${ }^{4}$ For a more detailed discussion of child labour supply see Cigno and Rosati (2005)
} 
their child to school then they need to commit a predetermined amount of the child's time to commuting to and from school and attending classes. ${ }^{5}$

More formally, households maximize the following utility function:

$$
\begin{array}{rlll}
\max _{C, L, S} U(C, L, S) & & \\
\text { s.t. } & S=S^{p}+S^{c}, & S^{c}=0,1, & C=Y_{0}+w H-e S^{c} \\
& H+L+S^{c} \varphi=1, & 0 \leq H, L \leq 1, & 0<\varphi<1
\end{array}
$$

where $C$ is household consumption, $L$ is child leisure, and $S$ is the child's level of education. The child's level of education $(S)$ is given by the sum of the number of years previously spent in school $\left(S^{p}\right)$ and current school attendance $\left(S^{c}\right) . S^{c}$ takes the value 1 if the household sends the child to school and 0 otherwise. Consumption $(C)$ is equal to the sum of the parent's exogenous income $\left(Y_{0}\right)$ and the revenues from child labour (which equal the child labour wage rate $(w)$ multiplied by the time the child spends working $(H))$ minus the monetary cost of an additional period of education $(e)$ consisting of formal and informal school fees, books, uniforms etc. If the child attends school it spends a fixed amount of time $(\varphi)$ commuting to school and attending classes. ${ }^{6}$ Total time available to the child for work $(H)$, leisure $(L)$, and schooling $\left(S^{c} \varphi\right)$ is normalized to 1 . In our model the cost of attending school thus includes both monetary costs $(e)$ and time costs $(\varphi)$.

Because of the non convexity in the child's time constraint (resulting from the fixed amount of time required by school attendance) households maximize an indirect utility function whose arguments are the maximum utility achievable when households respectively decide to enroll or not to enroll their child in school:

\footnotetext{
${ }^{5}$ As we show later in the paper, if pupils in our sample are enrolled in school they attend regularly: attendance rates for those enrolled are over 95\% according to multiple sources including unannounced spot checks. Hence, the assumption of spending a fixed amount of time in school seems reasonable.

${ }^{6}$ We do not consider study time and other inputs to education, as we are only concerned with school attendance.
} 


$$
\begin{aligned}
& \max _{S} U\left(U_{1}^{*}, U_{2}^{*}\right) \\
& =\max \begin{cases}U_{1}^{*}=\max _{L} U\left(Y_{0}+w(1-L), L, S^{p}\right) & S^{c}=0 \\
U_{2}^{*}=\max _{L} U\left(Y_{0}+w(1-L-\varphi)-e, L, S^{p}+1\right) & S^{c}=1\end{cases}
\end{aligned}
$$

For either enrollment state $\left(S^{c}=0,1\right)$, child work $(H)$ is implicitly determined by equalizing the marginal rate of substitution between consumption and leisure $\left(U_{L}^{\prime} / U_{C}^{\prime}\right)$ to the wage rate $(w)$. If $U_{L}^{\prime} / U_{C}^{\prime}>w$ at $H=0$ we have a corner solution and the child does not work $(\forall S=0,1)$. The model thus allows for four possible combinations of work and education: work only, school attendance only, school attendance and work, or neither.

What happens to school participation and child work when a program such as BRIGHT is implemented? To answer this question, recall that BRIGHT consists of two main components (described in more detail below). First, BRIGHT builds new schools, which reduces the time pupils spend commuting to and from school and thus the fixed time devoted to education $(\varphi)$. Second, BRIGHT provides direct incentives in the form of school meals (to both boys and girls) and take-home rations (to girls only), which implicitly reduces the monetary cost of education $(e)$.

The impact of BRIGHT on school participation is uniform. Both components of the program (a reduction in the cost of education $(e)$ and in the fixed time devoted to education $(\varphi)$ ) unambiguously raise $U_{2}^{*}$ with respect to $U_{1}^{*}$ for any value of $\mathrm{H}$. Hence, children who were in school will continue to be in school. Children who were not in school will begin to attend school if the interventions result in a sufficient increase in the (indirect) utility of school participation. Otherwise, they remain out of school. The overall effect of a program such as BRIGHT on school participation is thus unambiguously nonnegative. 
Next, we look at the more complex effect of BRIGHT on child work. A summary of this discussion can be found in Table 1. First, the work status of children who were and remain out of school is not changed. If they were not working before the reduction in the cost of education, they will not start working. If they were working, they will continue working with the same intensity. This claim can readily be verified, as the monetary cost of education $(e)$ and fixed time spent in school $(\varphi)$ do not enter the utility function in this case.

The theoretical prediction of changes in work status for children who were in school and remain in school is more complex. On the one hand, these pupils experience a reduction in the fixed time they spend in school $(\varphi)$, which lowers their marginal utility of leisure. On the other hand, they experience a reduction in the costs of education $(e)$, which reduces the marginal utility of household consumption. The former effect may be expected to increase children's propensity to work while the latter effect (which is stronger for girls as they also receive take-home rations) may be expected to reduce their propensity to work. The aggregate change in work participation depends on the relative importance of these two effects.

Working children who begin to attend school following the intervention also experience two opposing effects on their participation in work $(H)$. On the one hand, the marginal utility of leisure increases as the child has to spend part of its time $(\varphi)$ at school. On the other hand, the marginal utility of consumption (and thus of child work) increases as households now face the cost of education $(e)$. Children will stop working only if the increase in the marginal utility of leisure is large with respect to the increase in the marginal utility of consumption. By the same token, children who were neither working nor attending school might start working when they begin to attend school following a reduction in the cost of education $(e)$ or in the fixed time devoted to education $(\varphi)$, if the increase in the marginal utility 
of income with respect to that of leisure is large. Again, the income effect will be greater for girls, as they also receive a take-home ration.

We have in the model assumed that households have only one child. If this were not the case, then spillover effects might occur. Consider a household which has both a male and a female child. The girl will receive a take-home ration if she attends school in addition to the benefits that are also received by boys. This take-home ration will further reduce her cost of education and at the same time increase the overall resources potentially available to the household. If there is at least some degree of income pooling within the household, it is possible to observe spillover effects of the takehome rations provided to girls on boys belonging to the same household. Such spillover income effects, if present, will increase the probability that a male child attends school and decrease the probability that he works.

In summary, following a reduction in the cost of education, school attendance will increase (or in the limit remain the same): some of the children who were previously not in school will enroll and the children who were already in school will remain enrolled. There is no such clear theoretical prediction for the change in child work. Among children who remain out of school the prevalence of child labour should remain constant. Among children who remain in school or switch into school the change in the prevalence of child work is ambiguous. Finally, if there is some degree of income pooling, we can expect spillover income effects on male siblings of eligible girls. Although we cannot unambiguously predict the overall change in child work following a reduction in the cost of education, we can predict that the number of children working only will decrease, because some of these children will begin to attend school and possibly stop working. We should also observe a decrease in the share of children involved in neither activity as some of these children might enroll in school and possibly start working. 


\section{Setting, Study Design, and Data ${ }^{7}$}

\subsection{Education and Child Labour in Burkina Faso}

Burkina Faso is a poor landlocked country in western Africa. In 2008 it had roughly 16 million inhabitants, over $45 \%$ of which were children under the age of 15 and $80 \%$ of which lived in rural areas. Average life expectancy was 54 years and, with a per capita PPP $\mathrm{GNI}^{8}$ of US\$1130, Burkina Faso was one of the poorest countries in the world. ${ }^{9}$

Primary education in Burkina Faso is officially free of charge. In practice, however, schools typically do ask pupils for a contribution. School participation is nominally compulsory until the age of 16 and children are supposed to attend primary school for 6 years, between the ages of 6 and $12 .^{10}$ However, access to (particularly secondary) education is often limited, especially in rural areas. The government of Burkina Faso supports several initiatives to improve access to schooling and promote girls' education in particular. One of these initiatives is a 10-year plan (2002-2011) for the development of basic education. Activities implemented as part of this 10-year plan included the construction and restoration of primary schools.

Burkina Faso’s education statistics are bleak but improving. In 2006, $37 \%$ of 5 to 14 year old children were attending school. School attendance of boys (40\%) exceeded that of girls (33\%) and attendance was substantially higher in urban areas (67\%) than in rural areas (32\%). ${ }^{11}$ Although attendance rates were comparatively low, the country has made substantial progress in education outcomes over the past decades. In 2006, the primary school completion rate (\% of relevant age group) was 31\%, up from $10 \%$ in 1981 .

\footnotetext{
${ }^{7}$ This section heavily draws on and quotes from the original impact evaluation by Levy et al. (2009).

${ }^{8}$ Atlas method, current international US\$

${ }^{9}$ World Development Indicators Database, The World Bank. Accessed November 2011.

${ }^{10}$ At the end of the $6^{\text {th }}$ grade in primary school a national exam determines whether pupils can proceed to secondary school.

${ }^{11}$ UCW database ( www.ucw-project.org )
} 
The 2006 literacy rate was 39\% among 15 to 24 year old youths, up from 20\% in $1991 .^{12}$

Children in Burkina Faso are widely engaged in economic activities: in 2006 approximately 38\% of all 5 to 14 year old children was economically active. This number can be broken down as follows: $27 \%$ of 5 to 14 year old children was involved only in economic activities, $11 \%$ combined school with economic activities. ${ }^{13}$ On average, economically active children spent 21 hours a week on economic activities. The number of working hours was higher for economically active children who were not in school (24 hours) than for those who were in school (13 hours). Participation in economic activities was neither balanced across boys (44\%) and girls (31\%) nor across rural (41\%) and urban areas (20\%). Children's economic activities were primarily in agriculture (69\%) and domestic work in third party households (22\%) and most of the work performed by children was not remunerated.

It is also common for children to be involved in household chores: in 2006 roughly $60 \%$ of 5 to 14 year old children participated in chores. Children who performed chores spent on average 15 hours a week on these activities. Engagement in chores differed across gender groups: prevalence was $76 \%$ among girls and 45\% among boys and (for those engaged in chores) hours spent per week on chores was 17 for girls and 12 for boys.

\subsection{The BRIGHT Program}

The BRIGHT program aimed to improve education outcomes of children in rural villages in Burkina Faso. The program was financed by the Millennium Challenge Corporation (MCC) and implemented by a consortium of NGOs under the supervision of USAID. ${ }^{14}$ In 2005, the program started to

\footnotetext{
${ }^{12}$ World Development Indicators Database, The World Bank. Accessed November 2011.

${ }^{13}$ UCW database ( www.ucw-project.org )

14 The following NGOs implemented the program: Plan International, Catholic Relief Services, Tin Tua, and the Forum for African Women Educationalists
} 
implement an integrated package of education interventions in 132 rural villages.

The package of interventions included two main components. First, a school was built in each of the intervention villages. The construction work started around October 2006 and finished around April 2007. Second, direct incentives in the form of school kits, textbooks, and school meals for all pupils, and take-home rations of dry rice for girls with a monthly attendance rate of $90 \%$ or higher, were provided to encourage children's school participation. Additionally, in all the villages a range of advocacy measures took place. More details on the interventions can be found in Appendix A.

\subsection{Assignment of Villages to the BRIGHT program}

The BRIGHT program was implemented in 49 departments of the 10 provinces that have the lowest girls' primary completion rates in Burkina Faso. ${ }^{15}$ Each of these 49 departments was allowed to nominate villages to be considered for participation in the BRIGHT program. In total, the departments nominated 293 villages. Out of these villages 132 were selected to participate in the BRIGHT program. Villages were selected according to the following selection procedure.

First, each of the nominated villages was visited by a staff member of the Ministry of Education who assisted representatives of the village in completing an application form consisting of 16 questions. The responses to these questions were then used to assign each village a numerical score. Table 2 presents the 16 questions and the weights assigned to these questions to construct the numerical score.

Within each department, the villages were then ranked based on this numerical score and those in the top half were selected to receive a BRIGHT school. In the event of an odd number of villages, the median village did not

\footnotetext{
15 These provinces are: Banwa, Gnagana, Komandjari, Namentenga, Oudalan, Sanmentenga, Seno, Soum, Tapoa, and Yagha
} 
receive a school. Two departments nominated only one village. These villages were both selected to receive a BRIGHT school. This process generated a set of 138 villages that should have participated in the BRIGHT program. However, in the end only 132 of these 138 villages were selected because of limited funding.

\subsection{Data}

Mathematica Policy Research, Inc. (MPR) was hired to evaluate the BRIGHT program. As part of the evaluation, MPR in turn hired a team of researchers from the University of Ouagadougou to survey households and schools within the 293 villages that applied to the program. Data were only collected at the end of the program, there is no baseline available. The dataset contains data for 287 of the 293 villages. This subsection provides a brief overview of the data collection efforts. ${ }^{16}$ The final dataset is publicly available on the MCC website. ${ }^{17}$

\subsubsection{The Household Survey}

The household survey was administered in the spring of 2008. In each village, 30 households with school-age children (5 to 12 years old) were randomly selected to be surveyed. ${ }^{18}$ To develop the village-level household sampling frame, data collectors first conducted a complete census of households in each village. In that census, they identified households with school-age children and collected information about the household's access to

\footnotetext{
${ }^{16}$ Data for 6 villages are missing for the following reasons: 2 villages could not be located by data collectors (this is likely due to villages whose names differed either because of the dialect or an incorrect spelling recorded on the application form), 2 villages were from the departments that nominated only one village (and are thus are not suitable for regression discontinuity analysis, more details provided below), and finally 2 villages were excluded because no data was available for them (without further explanation).

17 http://www.mcc.gov/pages/countries/impact/impact-evaluation-for-burkina-fasos-thresholdprogram/burkina-faso-threshold-program

${ }^{18}$ Households were defined as a group of persons, living together (in a common physical space), working together under the authority of a person called "head of household" and taking their meals together, or from the same supply of food. The members of household must have lived together in this fashion during at least 9 of the previous 12 months.
} 
beasts of burden. Once the sampling frame at the village level was complete, it was stratified by access to beasts of burden, which served as a proxy for wealth. Three strata were identified: households who owned at least one beast of burden, households who did not own but had access to one, and households who neither owned nor had access to one. This method of stratification was suggested by researchers at the University of Ouagadougou in order to ensure a representative household sample, under hypothesis that the means of production is positively correlated with income. From each of these strata, 10 households were randomly chosen to be surveyed. ${ }^{19}$ The household survey was conducted with the head of household or another knowledgeable member of the household. ${ }^{20}$ The questionnaire contained one section collecting general information on the household (religion, ethnicity etc.) and the house in which it resides (construction materials, water source etc.).

The survey also collected specific information on all 5 to 12 years old children in the household, including sections on their participation in education and work. In particular, we use the information on school enrollment in the 2007-2008 school year, school attendance in the week prior to the interview, economic activities for someone who is not a member of the household (either remunerated or not) in the week and year prior to the interview, economic activities conducted for the household ${ }^{21}$ in the week prior to the interview and household chores ${ }^{22}$. Appendix B reports the questions on which the variables are based.

\footnotetext{
${ }^{19}$ For each stratum, the selection was done by writing the names of each head of an eligible household on a piece of paper, placing those pieces of paper in a hat, and then drawing 10 names. The selection process was carried out in a public manner in each village.

20 The questionnaire was based on several existing questionnaires widely used in developing countries including the Demographic and Health Survey (USAID), the Multiple Indicator Cluster Survey (UNICEF), and the Living Standards Measurement Study (World Bank).

${ }^{21}$ Economic activities for the household include : tending for animals, helping with farming, helping with shopping, or doing other family work (for example in a business or selling goods in the street).

${ }^{22}$ Household chores include the following activities: collecting firewood, cleaning, fetching water, and taking care of younger siblings.
} 
We also use the results of a mathematics and French test administered to each of the 5 to 12 year old children in the household as part of the household survey. The mathematics test contains 11 questions to see whether children are able to (i) identify written numbers, (ii) count, (iii) say whether one number is higher or lower than another, (iv) add numbers, and (v) subtract numbers. The French test contains 8 questions to see whether children can (i) identify written letters, (ii) read simple words, (iii) read more complicated words, and (iv) identify a missing word in a sentence.

\subsubsection{The School Survey}

A school questionnaire was administered in addition to the household survey in the spring of 2008. ${ }^{23} 24$ Data collectors first determined the total number schools, if any, that children from each village attended regularly on the basis of information provided by the village elders. The three schools closest to the village center (at a maximum distance of 10 kilometers) were then selected to be surveyed. A total of 360 schools was identified through this procedure.

When possible, the school survey was conducted with the school director. It collected information on the school, its personnel, and (in the spring 2008 follow-up school survey) on the school attendance of children identified in the household survey. ${ }^{25}$ For the latter module, the interviewer

\footnotetext{
${ }^{23}$ A first wave of school surveys was conducted in the fall of 2007, but this paper does not use data from that first wave.

24 Both the household and school questionnaire were first written in English and then translated into French. Since French is rarely spoken in rural villages, the French version of the household questionnaire then had to be translated into many different languages (sixtyeight languages are currently spoken in Burkina Faso). Faced with the prospect of surveying people in so many different languages, MPR determined that the best approach was to hire interviewers fluent in both French and local languages and train them to translate the instrument as they conducted the interview. The questionnaires were piloted in 5 intervention and 5 control villages and adjusted (shortened) according to the findings of the pilot before being implemented.

${ }^{25}$ Matching of children identified in the household survey with children in the schools was done while interviewers were in each village. Interviewers first completed the household surveys. They then compiled and populated the school attendance roster with the names of all children identified in the household surveys as being enrolled in a local school. They included
} 
conducted a roll-call and noted any absences. In addition, the teachers in the school were asked "Of the last three days the school was open, how many did the student attend?” In this paper we use both the roll-call data and the attendance information obtained from the teachers.

\section{Estimation Strategy and Results}

\subsection{Regression Discontinuity Estimation Strategy}

As explained above, villages were assigned to the BRIGHT program on the basis of a numerical score (henceforth the forcing variable). Within each department, only the villages ranking in the top half of the distribution were selected into the BRIGHT program. This assignment procedure implicitly identifies a threshold in the forcing variable within each department. We exploit these thresholds in a regression discontinuity framework to identify the causal effect of the BRIGHT program on child work. ${ }^{26}$ The intuition behind the regression discontinuity design is that villages with a forcing variable just below the threshold score are similar to villages with a forcing variable just above the threshold. These villages therefore serve as a valid control group to measure the impact of the BRIGHT program.

Formally, we identify the impact of the BRIGHT program by estimating the following sharp regression discontinuity equation:

$$
Y_{v i}=\alpha+\beta D_{v}+\sum_{k \geq 1} \gamma_{k}\left(X_{v}-c\right)^{k}+\sum_{k \geq 1} \delta_{k} D_{v}\left(X_{v}-c\right)^{k}+\mathbf{\vartheta Z}_{\mathbf{i}}+\varphi_{\mathrm{v}}+\varepsilon_{i}
$$

the child's household ID and household listing number on the roster. These identifiers were used later to link the school data to the household data. Once in the school, interviewers used the roster to collect attendance and enrollment information only for those children on that roster.

${ }^{26}$ The regression discontinuity approach was first introduced by Thistlethwaite and Campbell (1960) and later formalized by Hahn et al. (2001). Recent advances in the use of regression discontinuity methods are documented by Imbens and Lemieux (2008) and Lee and Lemieux (2010). 
where $Y_{v i}$ is the outcome of interest for individual $i$ in village $v, \alpha$ is the intercept, $D_{v}$ is a dummy taking the value 1 if a village was selected into the BRIGHT program (i.e. had a forcing variable score above the implicit threshold), the term $\sum_{k \geq 1} \gamma_{k}\left(X_{v}-c\right)^{k}$ is a polynomial of order $k$ that approximates the relationship between the outcome of interest and the distance of a the village's forcing variable $X_{v}$ from the threshold value $c$. The term $\sum_{k \geq 1} \delta_{k} D_{v}\left(X_{v}-c\right)^{k}$ includes the dummy for selection into the BRIGHT program $D_{v}$ and thus allows for a different functional form of the polynomial above and below the threshold score. $\mathbf{Z}_{\mathbf{i}}$ is a vector of individual and household level control variables and $\varphi_{\mathrm{v}}$ represents department fixed effects. The error term $\varepsilon_{i}$ captures all other determinants of the outcome of interest. The estimated coefficient $\beta$ gives the average local effect of a village being selected into the BRIGHT program.

Because the villages are selected into the BRIGHT program at the department level, the threshold score for participation in the BRIGHT program differs across departments. Following Levy et al (2009), we normalize forcing variables across districts by centering the threshold values of each department at $0 .{ }^{27}$ We estimate polynomials of orders 1,2 , and 3 and, following Lee and Lemieux (2010), we use the Akaike information criterion (AIC) to obtain an indication of the optimal order of the polynomial. We cluster standard errors at the village level.

The regression discontinuity approach will yield consistent parametric estimates of BRIGHT's average treatment effect if the specified polynomial correctly approximates the relationship between the distance of the village's forcing variable from the cutoff scores $\left(X_{v}-c\right)$ and outcome $Y_{v i}$. Misspecification becomes more likely when observations further from the cutoff score are used. We therefore check for the robustness of the estimated results within multiple bandwidths around the cutoff scores. We show which

\footnotetext{
${ }^{27}$ This normalization procedure maintains the relative distance of each village score from the threshold.
} 
of the presented bandwidths $(h)$ are preferred using the following crossvalidation criterion proposed by Imbens and Lemieux (2008):

$$
C V_{y}(h)=\frac{1}{n} \sum_{1}^{n}\left(Y_{v i}-\hat{Y}\left(\mathrm{X}_{\mathrm{v}}\right)\right)^{2} c
$$

where the preferred bandwidth is given by:

$$
h_{C V}^{o p t}=\operatorname{argminC} V_{y}(h)
$$

This cross-validation criterion minimizes the mean squared differences between actual and estimated outcomes. In doing so, the cross-validation criterion balances the precision of the estimates (which increases with the bandwidth) against the bias that may result from using too large a bandwidth.

\subsection{Validity of the Regression Discontinuity Approach}

The assignment procedure on the basis of the forcing variable, outlined above, appears to have been executed carefully. Nearly all of the 287 villages in the data were correctly assigned to the intervention and the control group on the basis of their forcing variables. Of the 136 villages in the data that should have received the BRIGHT program only 11 did not receive the intervention. ${ }^{28}$ Of these 11 villages, 6 were not selected because the program funds were insufficient and 5 were later discarded because their location proved inappropriate (for instance because there was no suitable water source). ${ }^{29}$ Four villages that should not have been selected were selected. Levy et al (2009) indicate that the villages that were selected, but should not have been selected, were the next highest in the ranking within their department. This suggests

\footnotetext{
${ }^{28} 9$ of the latter villages had effective normalized forcing values of 0 , i.e. they were at the cutoff point.

${ }^{29}$ No information is available to distinguish between the villages discarded for lack of funds and the villages discarded for inappropriate locations.
} 
that within these departments the BRIGHT intervention was assigned to the next highest ranked on the basis of the forcing variable.

Given that the number of incorrectly selected villages is small, we decided to remove them from the data instead of pursuing a fuzzy regression discontinuity estimation procedure. (Fuzzy regression discontinuity estimates, not displayed in this paper but available on request, are very similar to the results presented below.) We also removed any departments that, as a result of removing incorrectly selected villages or narrowing the bandwidth, have only villages above or below the threshold remaining and are therefore not suitable for regression discontinuity analysis.

The validity of the regression discontinuity approach rests on the assumption that, except for participation in the BRIGHT program, the marginal villages (i.e. the villages just above and below the threshold in each department), were similar at baseline. As the BRIGHT program did not collect baseline data (other than the information, not available to us, collected through the application form) a direct test for the similarity of the marginal villages is not possible. However, we can use the household and school survey data collected at the end of the program to see if variables that are not likely to be affected by the program are indeed similar in the marginal villages. ${ }^{30}$

Table 3 provides the descriptive statistics for a series of observed household and child characteristics and tests for differences across villages above and below the threshold. The characteristics considered include the education, religion and ethnic group of the household head, the age of the children and their relationship to the household head, the characteristics of the dwelling and the possession of durable goods. The test is carried out

\footnotetext{
${ }^{30}$ McCrary (2008) proposed to look at the density of the forcing variable around the threshold score to gauge the validity of the regression discontinuity approach. Irregularities in the density could signal that the forcing variable has been manipulated by (potential) beneficiaries, which would invalidate the regression discontinuity design. The McCrary (2008) approach, however, cannot be used for the Burkina Faso BRIGHT data. The reason for this is that threshold scores are only implicitly determined: within each district the forcing variable of the marginal selected village represents the threshold score. As a result, villages are by definition bunched just above the cutoff score.
} 
estimating equation (1) for each of the observed characteristics. Estimates are based on a second order polynomial and are given for 3 different bandwidths around the threshold score. The estimates do not include any controls other than the polynomial terms and the department fixed effects.

Overall the estimates suggest that differences between households and children living in villages just below or just above the threshold score are limited. Children in the marginal intervention villages are somewhat less likely to be male and are slightly younger (columns (1), (2), and (3)). Households in the intervention villages are somewhat less likely to own a bicycle or an animal cart and somewhat more likely to own a motor cycle (columns (5), (6), and (7)). The magnitude of these differences is fairly small and we feel confident that the households in the villages just below the threshold score serve as a valid control group in the regression discontinuity analysis presented in this paper.

\subsection{Results}

\subsubsection{Overall Impact on School Participation and Child work}

While BRIGHT substantially increased school participation it also resulted in a modest increase in children's participation in work. Figures 1 and 2 respectively examine the overall impact of BRIGHT on school participation and child labour. The horizontal axes of the graphs display the distance of the village forcing variable to the threshold score for selection into the BRIGHT program. Negative scores indicate the extent to which the forcing variable falls short of this cutoff point and vice versa for positive scores. The vertical axes respectively depict the fraction of children attending school (self-reported) and the fraction participating in work and chores. Dots depict local averages and the lines are fitted quadratic regressions.

Figure 1 shows that self-reported school enrollment in the 2007-2008 school year increased substantially as a result of the BRIGHT program. At the threshold, the proportion of children enrolled in school is approximately 15 
percentage points higher in BRIGHT villages than in control villages. ${ }^{31}$ Below -section 4.3.4 and Table 7- we show that school enrollment and school attendance figures are virtually identical. Figure 2 shows that the pronounced increase in school enrollment, is not accompanied by a decrease in children's participation in work in the 7 days prior to the interview (where work is defined as the combination of all economic activities and household chores identified in the household survey, see Appendix B). Instead, participation in work appears to increase modestly at the threshold.

Table 4 quantifies these graphical results. For the two outcomes presented in figures 1 and 2 the table shows estimates of the discontinuity at the threshold score for polynomials of order 1-3 and for 3 different bandwidths. ${ }^{32}$ These estimates by and large confirm the graphical findings. The probability of being enrolled in school (39\% in the overall sample, column (10)) has increased substantially. Estimates hover between 11 and 17 percentage points. The probability of participating in work ( $75 \%$ in the overall sample) did not decrease in any of the estimates. If anything, in accordance with the graphical evidence, the results suggest that there is a modest (borderline significant) increase in the probability of participating in work. The program thus generated a substantial increase in school participation without reducing -in fact even increasing- children's participation in work. The following subsections further disentangle and explain this finding.

\subsubsection{Disaggregated Impact on School Participation and Child work}

Because the content of BRIGHT differed for boys and girls (girls receive take-home rations conditional on sufficient school attendance, while boys do not), we assess whether the effects of BRIGHT were different for the following three groups of children: girls, boys without female siblings, and

\footnotetext{
31 A similar figure can be found in the original impact evaluation report of the BRIGHT program (see Levy et al, 2009).

32 The regressions in Table 4 (and all following tables) include the household and child characteristics discussed above (in Table 2) as controls.
} 
boys with female siblings (who may experience a spillover effect from their siblings take-home rations). ${ }^{33}$ Figure 3 shows the impact of BRIGHT on school participation and work for each of these three subgroups. Panel A of Table 5 again quantifies these graphical results. ${ }^{34}$

We observe substantial increases in school participation in all three subgroups. The increase appears to be somewhat stronger for girls and boys with female siblings (both around 15 percentage points) than for boys without female siblings (around 10 percentage points). This finding is consistent with the fact that girls receive additional benefits and with the hypothesis that these additional benefits are shared within the household. Child work is not reduced as a consequence of the increase in school participation. On the contrary, child work increased substantially for boys without female siblings (7 to 15 percentage points). Girls and boys with female siblings experience no change or perhaps a modest increase in work ( 0 to 7 percentage points and not highly significant).

Panel B shows that the observed changes in school participation are accompanied by a similar increase in the fraction of children who are both in school and in work within all three subgroups (roughly 10 to 16 percentage points). There are three potential explanations for this increase in participation in both activities: (i) children who were previously working only entered school without stopping to work, (ii) children who were previously in school only entered work without quitting school, or (iii) idle children entered both activities. We now explore these potential explanations in more detail for each of the three subgroups. ${ }^{35}$

Among girls, we observe a strong shift from participation in work only to participation in both activities (11 to 15 percentage points). This figure

\footnotetext{
${ }^{33}$ For brevity, we do not show a table with discontinuities in covariates (similar to table 3 ) for these 3 subgroups. Those tables, however, are available from the authors on request.

${ }^{34}$ We show results for three different bandwidths of second order polynomial regressions, results for different polynomial orders are available on request

${ }^{35}$ For brevity we do not show further graphs, but the graphical evidence (available on request) is in accordance with the results in the table.
} 
suggests that a substantial number of girls entered school without stopping to work. Within this subgroup there also appears to have been a modest shift from participating in none of the activities to participating in both activities (0 to 5 percentage points). Among boys without female siblings we observe the opposite pattern. They experience a strong decrease in the probability of being idle (7 to 10 percentage points) and no significant decrease in the probability of working only. Hence, it appears that many of these boys begin working and attending school at the same time. Boys with female siblings appear to be between these two extremes, as they experience both a decrease in the probability of working only (6 to 11 percentage points) and a decrease in the probability of being idle (5 to 11 percentage points). There is no compelling evidence of a change in the proportion of children who only attend school for any of the three subgroups. The point estimates are sometimes positive, sometimes negative, and with one exception at the $10 \%$ level none of them are statistically significant. $^{36}$

Without baseline information it is not possible to conclusively explain what shifts in activity status explain these findings. However, these results are in accordance with the theoretical model presented earlier. The model showed that children who were initially working but not in school may well continue working when they switch into school as a result of the program. Children who were previously idle may start working if they switch into school, depending on the relative changes in the marginal utility of consumption and leisure.

\subsubsection{A Closer Look at the Impact on Child Work}

We have just seen that the BRIGHT program increased the school attendance of working children and the prevalence of work. Now we investigate whether these changes are accompanied by changes in the kind of work children are carrying out and in the intensity of child work.

${ }^{36}$ Graphical evidence, not displayed here, supports this finding. 
First, as shown in Table 6, only a comparatively small fraction of the surveyed children was involved in economic activities for someone who is not a member of the household in the 7 days prior to the interview. This fraction was somewhat higher among boys without female siblings (8\%) than among other children (5\%). The BRIGHT program did not significantly affect these proportions, nor did it affect the intensity with which children are engaged in these activities. Children who were involved in economic activities for someone who is not a member of the household spent on average 7 to 8 hours per weeks on this activity and this figure is not discontinuous at the threshold. The coefficients are sometimes negative and sometimes positive and never statistically significant. Apparently, children did not alter their participation in economic activities outside the household in response to BRIGHT and the changes in child work observed above must take place within the household.

Indeed we find evidence of a discontinuity in participation in work for the household at the threshold score. A substantial number of children participated in work for the household in the 7 days prior to the interview (70\% of boys without female siblings, $73 \%$ of boys with female siblings, and $78 \%$ of girls). In marginal BRIGHT villages boys increased their participation in these activities. Point estimates range from 7 to 15 percentage points for boys without female siblings and from 3 to 7 percentage points for boys with female siblings. Information on working hours is not available for these activities (section 3 of this paper indicates that these hours are typically substantial (double digits)). We do have evidence on the number of different economic activities and chores children conducted for the household in the week prior to the interview. On average, children who indicated that they participate in work for the household conducted 2.1 to 2.8 such activities. The number of activities is again not affected by the BRIGHT program.

Finally, we look at two other indicators of economic activities conducted for someone not a member of the household: remunerated economic activities conducted in the 7 days prior to the interview, and 
economic activities conducted in the year prior to the interview. We find that virtually none of the children conduct remunerated economic activities in both control and BRIGHT villages. Approximately 9 to $10 \%$ of the children conducted economic activities for someone who is not a member of the household in the year prior to the interview. Two of the estimates suggest a significant negative effect of the BRIGHT program on this outcome. However, as these estimates exceed the average proportion of children who conducted economic activities outside the household in the past year, they appear to be imprecise. The remaining estimates suggest that BRIGHT had no effect on economic activities outside the household in the year prior to the interview. Graphic results (not presented here) support the latter finding.

Overall, we conclude that BRIGHT affected primarily the extensive margin of work conducted for the household. There is no evidence that BRIGHT increased children's participation in work outside the household or that BRIGHT affected the intensive margin of child work.

\subsubsection{A Closer Look at the Impact on School Participation}

As shown above, the children who enrolled in school as a result of BRIGHT typically also (started to) work. If the participation in work keeps these pupils from attending school regularly, we would expect average school attendance rates to drop in marginal BRIGHT villages. To investigate this issue, we look at 3 measures of school attendance: self-reported attendance on the most recent day the school was open, teacher reported attendance in the 3 days prior to the school survey, and presence in school during the roll-call (each of these measures is, of course, conditional on being enrolled in school).

Table 7 shows that school enrollment is a remarkably good measure of school attendance. On average, among pupils who indicate that they are enrolled in school, self-reported attendance on the most recent day school was open is nearly $100 \%$, teacher reported attendance in the 3 days prior to the school survey is roughly 3 days, and presence in school during the roll-call is 
also nearly $100 \%$. This finding holds for all three subgroups of children considered. Accordingly, we observe virtually no discontinuity in the three measures of school attendance at the threshold. Given that we have no reason to doubt the accuracy of the data, we conclude that children who are enrolled in school (be it in a BRIGHT village or not) attend school regularly.

This result implies that children who enrolled as a response to the BRIGHT program (of whom the vast majority either continued to work or started to work) now see their daily activities increase substantially. School days in Burkina Faso typically last 5 hours (from 7AM until noon). Moreover, children in the BRIGHT data spend an average of 41 minutes commuting to and from school. Together these figures imply that, during a typical school week, children who start attending school as a result of the BRIGHT program spend over 28 hours on school participation and commuting to and from school that were previously available for other activities. Children who started attending school in response to BRIGHT and continued to work or (more importantly) started to work are, therefore, likely to have substantially reduced their leisure time.

\subsubsection{The Impact of BRIGHT on Pupil Learning}

Finally, we investigate the impact of the BRIGHT program on mathematics and French test Z-scores. To calculate the Z-scores scores we separately sum the number of correct answers on the mathematics test (ranging from 0 to 11 ) and on the French test (ranging from 0 to 8) and then standardize by subtracting the mean test score and dividing by the standard deviation. If participation in work keeps pupils from learning in school, we would expect an impact of BRIGHT on pupil learning primarily among pupils who are not involved in these activities. To investigate this issue in more detail, we separate separately test the impact of the BRIGHT program among pupils who are in school only and among all other pupils. 
This analysis relies on the assumption that we can compare children who are in school only for marginal BRIGHT and non-BRIGHT villages. This assumption seems reasonable, given that we observe no clear discontinuity in the proportion of children involved only in school at the BRIGHT threshold (section 4.3.2 and Table 5 Panel B). ${ }^{37}$ For pupils who are in school only, the analysis then identifies the pure effect of better learning in school as a result of the BRIGHT program. For the other children (who are working when in school), the estimate represents the combined effect of a higher probability of being in school and of better learning when in school.

Table 8 shows that the BRIGHT program resulted in substantial improvements in French and mathematics test scores (roughly 0.2 to 0.4 standard deviations) for both subgroups. With one exception at the $10 \%$ level, Chow tests indicate that the improvements of mathematics and French test scores were similar among children who were in school only and all other children. We cannot know whether improvements in learning would have been more pronounced in the latter subgroup if BRIGHT had resulted in larger decreases in child labour. That being said, the results indicate that integrated education interventions such as BRIGHT can have a substantial impact on pupil learning even in settings where a large number of children combine school participation with work.

\section{Conclusion}

This paper uses data from Burkina Faso's BRIGHT program to show that improving access to education and providing school subsidies does not always reduce children's involvement in work, even if it does promote school attendance. BRIGHT aimed to increase school participation through the construction of primary schools and the provision of school meals and takehome rations to female pupils. This paper exploits an index-based assignment mechanism to identify the impact of the project on school participation and

\footnotetext{
${ }^{37}$ We acknowledge that without baseline data we cannot further substantiate this claim.
} 
child work. Our regression discontinuity estimates show that BRIGHT had a pronounced impact on school participation. However, the program was not accompanied by a reduction in child work. In fact, consistent with a theoretical model of children's time use, instead of preventing children from participating in work and chores, the interventions slightly increased children's participation in productive activities, possibly to finance their participation in education. The increased school attendance then mainly comes from reduced leisure.

We decompose this result for three subgroups (girls, boys without female siblings, and boys with female siblings) and take a closer look at the interaction between education and work to better understand the limited impact of the program on school participation. We find that working girls who enter school as a result of the program do not stop working. We also observe that some of the boys who were neither working nor attending school begin to work when the program induces them to enroll in school. Does the increase and the continued involvement of children in economic activities and household chores reduce the impact of the program on learning outcomes? While we cannot answer this answer conclusively, we show that even in the absence of a reduction in child work, the BRIGHT program substantially increased the learning outcomes of both working and not working children attending school.

We conclude that programs that reduce both the time and the monetary costs of education are not necessarily sufficient to reduce child labour even if they effectively increase school attendance. If education programs are implemented to achieve a combination of increased school participation and a reduction in child work they may either have to be combined with different interventions that effectively reduce child work or they may have to be tuned more carefully to the incentives and constraints the child laborer faces. 


\section{Appendix A: The BRIGHT Program}

In 2005, the BRIGHT program started to implement an integrated package of interventions in each of the 132 villages. This appendix provides a detailed description of the implemented interventions:

1. A primary school was constructed in each of the 132 BRIGHT villages. These schools were built according to a prototype with three classrooms, two multipurpose halls, one office, and one storage room. Construction also included teachers' lodgings situated close to the school, with two bedrooms, one living room, one kitchen, and one bathroom (latrine). BRIGHT provided each school with a borehole, equipped with a manual pump easy to use by children. Separate latrine blocks were built for girls and boys to ensure privacy and security. Schools also received equipment, including student desks, teacher desks, chairs, metal bookshelves, and playground equipment. Child care centers were constructed in 10 of the 132 school complexes. The construction work started around October 2006. By April 2007 most of the schools had been constructed.

2. In all BRIGHT schools, daily meals were offered to pupils (boys and girls) via a canteen. For both the schools and the child care centers, the monthly ration consisted of 5 kilograms of rice and 0.5 liter of oil per child.

3. Girls who achieved a 90-percent rate of school attendance received a monthly ration of 8 kilograms of dry rice to take home.

4. For the 2006-2007 school year, the project purchased and distributed school kits for first and second grade classes. That year, however, textbooks were not widely available. As a result, only 2,500 second grade textbooks were distributed. In 2007-2008, the government provided all schools, including BRIGHT schools, with kits and textbooks. 
5. A wide range of activities that sought to change socio-cultural behaviors presenting obstacles to girls' school enrollment, retention, and achievement was implemented over the course of the program. The purpose of these activities was to bring together communities and those with a stake in the education system to discuss the issues involved in, and barriers to, girls' education. The activities included informational meetings; door-to-door canvassing; gender-sensitivity training for ministry officials, pedagogical inspectors, teachers, and community members; a girls' education day; radio broadcasts; posters; and awards for female teachers. In the first year (school year 2006-2007), 33 selected communities benefited from the campaign. During the second project year (school year 2007-2008), the same activities were carried out in the remaining 99 communities and new activities were initiated for all 132 communities.

6. The program provided literacy training to adult females and mentoring to girl students. The rationale behind the literacy training was to provide uneducated mothers with non-formal education (literacy and micro-project management training) to help them prioritize their girls' education. Mentoring was meant to help girls and their families envision a productive future by providing them with female role models who could set examples of the benefits of education and encourage and support them during their school careers. In the first project year, 254 literacy centers were opened and recruited trainees. Ten centers did not open, or were closed shortly after opening, due to lack of interest.

7. Finally, the program included capacity building in the form of training provided to local officials in the Ministry of Education, child care center monitors, and teachers. The capacity building included training on completion of school registers. 


\section{Appendix B: Questions from Household Survey}

This appendix reproduces the questions from the household and school survey used to define the outcome variables of this study. Two questions were used from the household survey education section:

- During the 2007-2008 school year has (name) attended school or preschool at any time?

- Did (name) attend school on the most recent day school was open?

Eleven questions were used from the household survey child labour section:

- During the past week, did (name) do any kind of work for someone who is not a member of this household? (if yes: for pay in cash or kind?)

- Since last (day of the week), about how many hours did he/she do this work for someone who is not a member of this household? (if more than one job, include all hours at all jobs.)

- At any time during the past year, did (name) do any kind of work for someone who is not a member of this household?

- During the past week, did (name) help with collecting firewood?

- During the past week, did (name) help with cleaning?

- During the past week, did (name) help with fetching water?

- During the past week, did (name) help with taking care of younger siblings?

- During the past week, did (name) help tend animals?

- During the past week, did (name) help with farming?

- During the past week, did (name) help with shopping?

- During the past week, did (name) do any other family work (in a business or selling goods in the street?)

Finally, one question was used from the school survey:

- "Of the last three days the school was open, how many did the student attend?” 


\section{References}

Cigno, A. and F. C. Rosati (2005). The Economics of Child Labour, Oxford University Press

Edmonds, E. (2007). “Child Labor” ,in T. P. Schultz and J. Strauss, eds., Handbook of Development Economics, Volume 4 (ElsevierScience, Amsterdam, North-Holland)

Hahn, J., P. Todd, and W. Van der Klaauw (2001). “Identifcation and Estimation of Treatment Effects with a Regression Discontinuity Design.” Econometrica, 69 (1), 201-209.

Imbens, G. W. and T. Lemieux (2008). "Regression Discontinuity Designs: A Guide to Practice.” Journal of Econometrics, 142 (2), 615-635.

Kazianga, H., D. de Walque,, and H. Alderman (2008). “Educational and Health Impact of Two School Feeding Schemes: Evidence from a Randomized Trial in Burkina Faso.” Working Paper.

Kondylis, F. and M. Manacorda (2012). "School Proximity and Child Labor: Evidence from Rural Tanzania.” Journal of Human Resources, 47 (1), 32-63.

Lee, D. S. and T. Lemieux (2010). “Regression Discontinuity Designs in Economics.” Journal of Economic Literature, 48, 281-355.

Levy, D., M. Sloan, L. Linden, and H. Kazianga (2009). Impact Evaluation of Burkina Faso's Bright Program: Final Report, Mathematica Policy Research, Inc., Washington D.C., USA.”

McCrary, J. (2008). “Manipulation of the Running Variable in the Regression Discontinuity Design. ” Journal of Econometrics, 142 (2), 698714.

Ravallion, M. and Q. Wodon (2000). "Does Child Labour Displace Schooling? Evidence on Behavioural Responses to an Enrollment Subsidy.” Economic Journal, 110 (462), C158-C175. 
Thistlethwaite, D. L. and D. T. Campbell (1960). "RegressionDiscontinuity Analysis: An Alternative to the Ex-Post Facto Experiment.” Journal of Educational Psychology, 51, 309-317.

\section{Tables}

Table 1: Predicted changes in work status

\begin{tabular}{ccc}
\hline$\Delta$ school participation & Initial work status & $\Delta$ work status \\
(1) & $(2)$ & $(3)$ \\
\hline Stay out of school & Not working & 0 \\
Stay in school & Working & 0 \\
& Not working & + \\
Switch into school & Norking & - \\
& Working & - \\
\hline Column (1) gives the change in school participation as a result of \\
the reduction in costs of education. Column (2) represents the \\
work status of the child in absence of the reduction in the cost of \\
education. Finally, column (3) shows the change in work status \\
with a reduction in the cost of education: - = non-positive change, \\
$0=$ no change, $+=$ non-negative change.
\end{tabular}


Table 2: Construction of numerical score for selection of BRIGHT villages

\begin{tabular}{|c|c|c|}
\hline \multicolumn{2}{|c|}{ Question } & \multirow{2}{*}{$\begin{array}{l}\text { Weight } \\
1 \text { point per girl }\end{array}$} \\
\hline 1 & Number of 7-year-old girls in your village & \\
\hline 2 & $\begin{array}{l}\text { Number of girls between } 7 \text { and } 12 \text { years old in your } \\
\text { village }\end{array}$ & 1 point per girl \\
\hline 3 & $\begin{array}{l}\text { Number of girls between } 7 \text { and } 12 \text { years old in your } \\
\text { village that are in school }\end{array}$ & 1 point per girl \\
\hline 4 & Distance to travel to the nearest school & $\begin{array}{l}+1 \text { point if between } 0 \text { and } 5 \mathrm{~km} \text { and }-1 \\
\text { point for } 6 \mathrm{~km} \text { or more }\end{array}$ \\
\hline 5 & Number of students at the nearest school & 1 point per student \\
\hline 6 & Number of classrooms at the nearest school & $\begin{array}{l}+1 \text { if there are no rooms and }-1 \text { if there } \\
\text { are }\end{array}$ \\
\hline 7 & $\begin{array}{l}\text { Number of villages nearby (nearby villages include all } \\
\text { villages within a } 6 \mathrm{~km} \text { radius of your village) }\end{array}$ & $\begin{array}{l}+1 \text { for each village between } 0 \text { and } 5 \mathrm{~km} \\
\text { and }-1 \text { for each village of } 6 \mathrm{~km} \text { or more }\end{array}$ \\
\hline 8 & Number of schools for all nearby villages & $\begin{array}{l}-1 \text { for each existing school and } \\
+1 \text { if there are none }\end{array}$ \\
\hline 9 & $\begin{array}{l}\text { Distance to the closest school in these villages (listed in } \\
\text { question 7) }\end{array}$ & $\begin{array}{l}+1 \text { if between } 0 \text { and } 5 \mathrm{~km}-1 \text { if } 6 \mathrm{~km} \text { or } \\
\text { more }\end{array}$ \\
\hline 10 & $\begin{array}{l}\text { Number of girls between } 7 \text { and } 12 \text { years old in the } \\
\text { nearby villages }\end{array}$ & 1 point per girl \\
\hline 11 & Distance from your village to a high school & $\begin{array}{l}+1 \text { if between } 0 \text { and } 20 \mathrm{~km} \text { and }-1 \text { if } 21 \\
\mathrm{~km} \text { or more }\end{array}$ \\
\hline 12 & Number of students at the high school & +1 per student \\
\hline 13 & $\begin{array}{l}\text { What is your plan for assuring that all girls will be in } \\
\text { school? }\end{array}$ & $\begin{array}{l}+1 \text { for each relevant action or plan } \\
\text { suggested }\end{array}$ \\
\hline 14 & $\begin{array}{l}\text { What is your plan for helping with the unskilled labor } \\
\text { needed to build the [BRIGHT] school? }\end{array}$ & $\begin{array}{l}+1 \text { for each relevant action or plan } \\
\text { suggested }\end{array}$ \\
\hline 15 & $\begin{array}{l}\text { What is your plan for teaching the student }{ }^{\text {ee }} \text { s parents to } \\
\text { read and write? }\end{array}$ & $\begin{array}{l}+1 \text { for each relevant action or plan } \\
\text { suggested }\end{array}$ \\
\hline 16 & $\begin{array}{l}\text { How do you propose to participate in the management } \\
\text { of the [BRIGHT] school? }\end{array}$ & $\begin{array}{l}+1 \text { for each relevant action or plan } \\
\text { suggested }\end{array}$ \\
\hline
\end{tabular}


Table 3: Discontinuities in covariates

\begin{tabular}{|c|c|c|c|c|c|c|c|c|c|}
\hline Bandwidth & 100 & 250 & 500 & Mean & Bandwidth & 100 & 250 & 500 & Mean \\
\hline & (1) & (2) & (3) & (4) & & (5) & (6) & (7) & (8) \\
\hline \multicolumn{5}{|c|}{ Characteristics of the household head } & \multicolumn{5}{|l|}{ Characteristics of the house } \\
\hline Male & $\begin{array}{c}0.006 \\
(0.010)\end{array}$ & $\begin{array}{c}0.018 \\
(0.011)\end{array}$ & $\begin{array}{l}-0.011 \\
(0.009)\end{array}$ & 0.978 & Floor natural & $\begin{array}{c}0.028 \\
(0.029)\end{array}$ & $\begin{array}{l}-0.027 \\
(0.024)\end{array}$ & $\begin{array}{l}-0.010 \\
(0.019)\end{array}$ & 0.943 \\
\hline Not educated & $\begin{array}{c}-0.042 \\
(0.044)\end{array}$ & $\begin{array}{c}0.003 \\
(0.029)\end{array}$ & $\begin{array}{l}-0.001 \\
(0.024)\end{array}$ & 0.891 & Floor rudimentary & $\begin{array}{c}0.009 \\
(0.007)\end{array}$ & $\begin{array}{l}0.012 * \\
(0.007)\end{array}$ & $\begin{array}{c}0.003 \\
(0.006)\end{array}$ & 0.007 \\
\hline Muslim & $\begin{array}{r}-0.182^{*} \\
(0.100)\end{array}$ & $\begin{array}{l}-0.045 \\
(0.062)\end{array}$ & $\begin{array}{l}-0.030 \\
(0.056)\end{array}$ & 0.593 & Floor finished & $\begin{array}{l}-0.034 \\
(0.028)\end{array}$ & $\begin{array}{c}0.020 \\
(0.024)\end{array}$ & $\begin{array}{c}0.011 \\
(0.018)\end{array}$ & 0.047 \\
\hline Christian & $\begin{array}{c}-0.016 \\
(0.080)\end{array}$ & $\begin{array}{l}-0.006 \\
(0.040)\end{array}$ & $\begin{array}{l}-0.011 \\
(0.034)\end{array}$ & 0.133 & Roof natural & $\begin{array}{c}0.126 \\
(0.140)\end{array}$ & $\begin{array}{c}-0.051 \\
(0.084)\end{array}$ & $\begin{array}{c}0.029 \\
(0.063)\end{array}$ & 0.579 \\
\hline Animist & $\begin{array}{c}0.186 * * \\
(0.077)\end{array}$ & $\begin{array}{c}0.050 \\
(0.051)\end{array}$ & $\begin{array}{c}0.044 \\
(0.046)\end{array}$ & 0.264 & Roof rudimentary & $\begin{array}{l}-0.127 \\
(0.150)\end{array}$ & $\begin{array}{c}0.038 \\
(0.090)\end{array}$ & $\begin{array}{l}-0.020 \\
(0.067)\end{array}$ & 0.305 \\
\hline Moore (mother tongue) & $\begin{array}{c}-0.119 \\
(0.159)\end{array}$ & $\begin{array}{l}-0.028 \\
(0.082)\end{array}$ & $\begin{array}{l}-0.027 \\
(0.061)\end{array}$ & 0.365 & Roof finished & $\begin{array}{c}0.001 \\
(0.060)\end{array}$ & $\begin{array}{c}0.016 \\
(0.036)\end{array}$ & $\begin{array}{l}-0.008 \\
(0.029)\end{array}$ & 0.112 \\
\hline Fulfude (mother tongue) & $\begin{array}{c}0.002 \\
(0.153)\end{array}$ & $\begin{array}{c}0.049 \\
(0.075)\end{array}$ & $\begin{array}{c}0.063 \\
(0.055)\end{array}$ & 0.203 & Durable goods and cattle own & ned by the & householc & & \\
\hline Gulmachema (mother tongue) & $\begin{array}{l}-0.044 \\
(0.082)\end{array}$ & $\begin{array}{l}-0.051 \\
(0.060)\end{array}$ & $\begin{array}{l}-0.057 \\
(0.050)\end{array}$ & 0.287 & Radio & $\begin{array}{l}-0.098 \\
(0.061)\end{array}$ & $\begin{array}{l}-0.001 \\
(0.047)\end{array}$ & $\begin{array}{c}0.012 \\
(0.039)\end{array}$ & 0.563 \\
\hline Mossi (ethnicity) & $\begin{array}{l}-0.127 \\
(0.159)\end{array}$ & $\begin{array}{l}-0.035 \\
(0.082)\end{array}$ & $\begin{array}{l}-0.036 \\
(0.062)\end{array}$ & 0.372 & Mobile phone & $\begin{array}{l}-0.055 \\
(0.039)\end{array}$ & $\begin{array}{c}0.024 \\
(0.031)\end{array}$ & $\begin{array}{c}0.013 \\
(0.023)\end{array}$ & 0.138 \\
\hline Peul (ethnicity) & $\begin{array}{l}-0.006 \\
(0.152)\end{array}$ & $\begin{array}{c}0.037 \\
(0.073)\end{array}$ & $\begin{array}{c}0.051 \\
(0.053)\end{array}$ & 0.189 & Watch & $\begin{array}{l}-0.123 \\
(0.090)\end{array}$ & $\begin{array}{c}0.031 \\
(0.056)\end{array}$ & $\begin{array}{l}-0.012 \\
(0.045)\end{array}$ & 0.587 \\
\hline Gourmanche (ethnicity) & $\begin{array}{l}-0.027 \\
(0.083)\end{array}$ & $\begin{array}{l}-0.021 \\
(0.059)\end{array}$ & $\begin{array}{l}-0.028 \\
(0.049)\end{array}$ & 0.296 & Bicycle & $\begin{array}{c}-0.131^{* *} \\
(0.066)\end{array}$ & $\begin{array}{c}-0.078^{*} \\
(0.044)\end{array}$ & $\begin{array}{c}-0.081 * * \\
(0.035)\end{array}$ & 0.859 \\
\hline Characteristics of the child & & & & & Motor cycle & $\begin{array}{l}-0.060 \\
(0.042)\end{array}$ & $\begin{array}{l}0.053 * \\
(0.028)\end{array}$ & $\begin{array}{c}0.035 \\
(0.023)\end{array}$ & 0.210 \\
\hline Male & $\begin{array}{c}-0.030 \\
(0.034)\end{array}$ & $\begin{array}{c}-0.041 * * \\
(0.018)\end{array}$ & $\begin{array}{c}-0.036^{* *} \\
(0.014)\end{array}$ & 0.531 & Animal cart & $\begin{array}{c}-0.202 * * \\
(0.095)\end{array}$ & $\begin{array}{l}-0.026 \\
(0.056)\end{array}$ & $\begin{array}{l}-0.050 \\
(0.042)\end{array}$ & 0.444 \\
\hline Age (years) & $\begin{array}{c}0.210 \\
(0.129)\end{array}$ & $\begin{array}{l}0.146 * \\
(0.079)\end{array}$ & $\begin{array}{c}0.151 * * \\
(0.071)\end{array}$ & 8.118 & Cattle & $\begin{array}{c}-0.163 * \\
(0.083)\end{array}$ & $\begin{array}{c}-0.002 \\
(0.054)\end{array}$ & $\begin{array}{l}-0.030 \\
(0.044)\end{array}$ & 0.652 \\
\hline Son or daughter of head & $\begin{array}{r}-0.019 \\
(0.028) \\
\end{array}$ & $\begin{array}{l}-0.034 \\
(0.022) \\
\end{array}$ & $\begin{array}{r}-0.030 \\
(0.019) \\
\end{array}$ & 0.889 & & & & & \\
\hline Observations: villages (clusters) & 130 & 212 & 248 & 271 & Observations: villages (clusters) & 130 & 212 & 248 & 271 \\
\hline Observations: households & 3,830 & 6,263 & 7,219 & 7900 & Observations: households & 3,830 & 6,263 & 7,219 & 7900 \\
\hline
\end{tabular}

Notes: $* * * \mathrm{p}<0.01, * * \mathrm{p}<0.05, * \mathrm{p}<0.1$. Estimated discontinuities in covariates that we expect to be unaffected by the BRIGHT program. All estimates are

based on a second order polynomial and include department fixed effects. Standard errors (in parentheses) are clustered at the village level. Means are

calculated for the unrestricted sample of 271 villages. 
Table 4: Overall impact: discontinuities in the proportion of children enrolled in school and participating in economic activities and / or chores

\begin{tabular}{|c|c|c|c|c|c|c|c|c|c|c|}
\hline Bandwidth & 100 & 100 & 100 & 250 & 250 & 250 & 500 & 500 & 500 & \\
\hline \multirow[t]{2}{*}{ Polynomial } & 1 & 2 & 3 & 1 & 2 & 3 & 1 & 2 & 3 & Mean \\
\hline & $(1)$ & $(2)$ & (3) & $(4)$ & (5) & $(6)$ & $(7)$ & $(8)$ & $(9)$ & $(10)$ \\
\hline $\begin{array}{l}\text { Enrolled in school (2007-2008 school } \\
\text { year). }\end{array}$ & $\begin{array}{c}0.133^{* * *} \\
(0.042)\end{array}$ & $\begin{array}{l}0.125 * \\
(0.065)\end{array}$ & $\begin{array}{c}0.114 \\
(0.092)\end{array}$ & $\begin{array}{c}0.136 * * * \\
(0.031)\end{array}$ & $\begin{array}{c}0.159 * * * \\
(0.042)\end{array}$ & $\begin{array}{l}0.119 * * \\
(0.058)\end{array}$ & $\begin{array}{c}0.169 * * * \\
(0.028)\end{array}$ & $\begin{array}{c}0.125 * * * \\
(0.035)\end{array}$ & $\begin{array}{c}0.141 * * * \\
(0.047)\end{array}$ & 0.388 \\
\hline AIC & 10,555 & 10,545 & 10,549 & 17,761 & 17,755 & 17,744 & 20,591 & 20,565 & 20,563 & \\
\hline $\mathrm{CVC}$ & 0.1726 & 0.1725 & 0.1725 & 0.1783 & 0.1780 & 0.1780 & 0.1789 & 0.1788 & 0.1786 & \\
\hline $\begin{array}{l}\text { Participating in work in } 7 \text { days prior to } \\
\text { interview. }\end{array}$ & $\begin{array}{c}0.053 \\
(0.033)\end{array}$ & $\begin{array}{c}0.023 \\
(0.053)\end{array}$ & $\begin{array}{c}0.025 \\
(0.074)\end{array}$ & $\begin{array}{l}0.069 * * * \\
(0.026)\end{array}$ & $\begin{array}{c}0.033 \\
(0.035)\end{array}$ & $\begin{array}{c}0.073 \\
(0.045)\end{array}$ & $\begin{array}{c}0.010 \\
(0.023)\end{array}$ & $\begin{array}{l}0.072 * * \\
(0.029)\end{array}$ & $\begin{array}{c}0.036 \\
(0.035)\end{array}$ & 0.748 \\
\hline AIC & 9,351 & 9,346 & 9,337 & 15,203 & 15,190 & 15,186 & 17,651 & 17,574 & 17,556 & \\
\hline CVC & 0.1589 & 0.1589 & 0.1585 & 0.1595 & 0.1593 & 0.1592 & 0.1599 & 0.1594 & 0.1592 & \\
\hline Observations: children & 9,605 & 9,605 & 9,605 & 15,917 & 15,917 & 15,917 & 18,370 & 18,370 & 18,370 & 20289 \\
\hline
\end{tabular}

Notes: $* * * \mathrm{p}<0.01, * * \mathrm{p}<0.05, * \mathrm{p}<0.1$. Estimated discontinuities in the proportion of children enrolled in school and participating in economic activities and / or in chores at the threshold scores. All estimates include department fixed effects and include the variables displayed in table 2 as controls. Standard errors (in parentheses) are clustered at the village level. Means are calculated for the unrestricted sample of 271 villages. 
Table 5: Disaggregated impact: discontinuities in the proportion of children enrolled in school and participating in economic activities and / or chores

\begin{tabular}{|c|c|c|c|c|c|c|c|c|c|c|c|c|}
\hline \multirow{2}{*}{$\begin{array}{l}\text { Subgroup } \\
\text { Bandwidth } \\
\end{array}$} & \multicolumn{4}{|c|}{ Girls } & \multicolumn{4}{|c|}{ Boys without female siblings } & \multicolumn{4}{|c|}{ Boys with female siblings } \\
\hline & 100 & 250 & 500 & Mean & 100 & 250 & 500 & Mean & 100 & 250 & 500 & Mean \\
\hline & $(1)$ & $(2)$ & (3) & (4) & (5) & $(6)$ & (7) & (8) & (9) & $(10)$ & $(11)$ & $(12)$ \\
\hline \multicolumn{13}{|c|}{ Panel A: Shifts in school enrollment and work } \\
\hline $\begin{array}{l}\text { Enrolled in school (2007-2008 school } \\
\text { year). }\end{array}$ & $\begin{array}{l}0.123^{*} \\
(0.070)\end{array}$ & $\begin{array}{c}0.180 * * * \\
(0.047)\end{array}$ & $\begin{array}{c}0.154 * * * \\
(0.040)\end{array}$ & 0.397 & $\begin{array}{c}0.071 \\
(0.073)\end{array}$ & $\begin{array}{c}0.126 * * \\
(0.051)\end{array}$ & $\begin{array}{l}0.109 * * \\
(0.044)\end{array}$ & 0.376 & $\begin{array}{c}0.170^{* * *} \\
(0.066)\end{array}$ & $\begin{array}{c}0.157 * * * \\
(0.046)\end{array}$ & $\begin{array}{c}0.107 * * * \\
(0.039)\end{array}$ & 0.382 \\
\hline CVC & 0.1716 & 0.1752 & 0.1757 & & 0.1577 & 0.1632 & 0.1654 & & 0.1725 & 0.1780 & 0.1788 & \\
\hline $\begin{array}{l}\text { Participating in work in } 7 \text { days prior to } \\
\text { interview. }\end{array}$ & $\begin{array}{l}-0.013 \\
(0.056)\end{array}$ & $\begin{array}{c}0.017 \\
(0.037)\end{array}$ & $\begin{array}{l}0.050^{*} \\
(0.030)\end{array}$ & 0.778 & $\begin{array}{c}0.073 \\
(0.061)\end{array}$ & $\begin{array}{c}0.097 * * \\
(0.047)\end{array}$ & $\begin{array}{l}0.154^{* * *} \\
(0.038)\end{array}$ & 0.705 & $\begin{array}{c}0.039 \\
(0.062)\end{array}$ & $\begin{array}{c}0.032 \\
(0.039)\end{array}$ & $\begin{array}{l}0.074^{*} \\
(0.038)\end{array}$ & 0.729 \\
\hline CVC & 0.1391 & 0.1361 & 0.1352 & & 0.1523 & 0.1529 & 0.1581 & & 0.1591 & 0.1593 & 0.1594 & \\
\hline \multicolumn{13}{|l|}{ Panel B: Explanation of overall shift: } \\
\hline In both activities & $\begin{array}{l}0.111^{*} \\
(0.065)\end{array}$ & $\begin{array}{c}0.162 * * * \\
(0.042)\end{array}$ & $\begin{array}{c}0.158 * * * \\
(0.037)\end{array}$ & 0.311 & $\begin{array}{c}0.059 \\
(0.064)\end{array}$ & $\begin{array}{c}0.150 * * * \\
(0.044)\end{array}$ & $\begin{array}{l}0.161^{* * *} \\
(0.038)\end{array}$ & 0.248 & $\begin{array}{l}0.100^{*} \\
(0.059)\end{array}$ & $\begin{array}{c}0.137 * * * \\
(0.041)\end{array}$ & $\begin{array}{c}0.126 * * * \\
(0.035)\end{array}$ & 0.263 \\
\hline CVC & 0.1613 & 0.1642 & 0.1633 & & 0.1411 & 0.1399 & 0.1382 & & 0.1485 & 0.1529 & 0.1538 & \\
\hline Participating in work only & $\begin{array}{l}-0.125 \\
(0.083)\end{array}$ & $\begin{array}{c}-0.145^{* * *} \\
(0.053)\end{array}$ & $\begin{array}{c}-0.107^{* *} \\
(0.043)\end{array}$ & 0.468 & $\begin{array}{c}0.014 \\
(0.084)\end{array}$ & $\begin{array}{l}-0.053 \\
(0.060)\end{array}$ & $\begin{array}{l}-0.008 \\
(0.050)\end{array}$ & 0.457 & $\begin{array}{l}-0.061 \\
(0.071)\end{array}$ & $\begin{array}{c}-0.105^{* *} \\
(0.051)\end{array}$ & $\begin{array}{l}-0.052 \\
(0.045)\end{array}$ & 0.465 \\
\hline CVC & 0.2122 & 0.2134 & 0.2133 & & 0.2024 & 0.2027 & 0.2049 & & 0.2115 & 0.2158 & 0.2168 & \\
\hline Enrolled in school only & $\begin{array}{c}0.012 \\
(0.028)\end{array}$ & $\begin{array}{c}0.018 \\
(0.023)\end{array}$ & $\begin{array}{l}-0.003 \\
(0.018)\end{array}$ & 0.086 & $\begin{array}{c}0.013 \\
(0.036)\end{array}$ & $\begin{array}{l}-0.024 \\
(0.033)\end{array}$ & $\begin{array}{c}-0.052 * \\
(0.027)\end{array}$ & 0.129 & $\begin{array}{c}0.070 \\
(0.052)\end{array}$ & $\begin{array}{c}0.020 \\
(0.031)\end{array}$ & $\begin{array}{l}-0.018 \\
(0.027)\end{array}$ & 0.119 \\
\hline CVC & 0.0657 & 0.0680 & 0.0689 & & 0.0786 & 0.0855 & 0.0910 & & 0.0929 & 0.0941 & 0.0940 & \\
\hline In neither activity & $\begin{array}{c}0.002 \\
(0.043)\end{array}$ & $\begin{array}{l}-0.035 \\
(0.025)\end{array}$ & $\begin{array}{c}-0.047^{* *} \\
(0.020)\end{array}$ & 0.136 & $\begin{array}{l}-0.086 \\
(0.053)\end{array}$ & $\begin{array}{c}-0.073^{* *} \\
(0.033)\end{array}$ & $\begin{array}{c}-0.101^{* * *} \\
(0.028)\end{array}$ & 0.167 & $\begin{array}{l}-0.109 * \\
(0.056)\end{array}$ & $\begin{array}{c}-0.052 * \\
(0.030)\end{array}$ & $\begin{array}{c}-0.055^{* *} \\
(0.024)\end{array}$ & 0.152 \\
\hline CVC & 0.0904 & 0.0864 & 0.0843 & & 0.0979 & 0.0998 & 0.0993 & & 0.0948 & 0.0946 & 0.0934 & \\
\hline Observations: children & 4,453 & 7,491 & 8,611 & 9517 & 1,784 & 2,826 & 3,306 & 3584 & 3,368 & 5,600 & 6,453 & 7188 \\
\hline
\end{tabular}

Notes: ${ }^{* * *} \mathrm{p}<0.01,{ }^{* *} \mathrm{p}<0.05,{ }^{*} \mathrm{p}<0.1$. Estimated discontinuities in the proportion of children enrolled in school and participating in economic activities and / or in chores at the threshold scores. All estimates are based on a second order polynomial and include department fixed effects and the variables displayed in table 2 as controls. Standard errors (in parentheses) are clustered at the village level. Means are calculated for the unrestricted sample of 271 villages. 
Table 6: Economic activities and or chores

\begin{tabular}{|c|c|c|c|c|c|c|c|c|c|c|c|c|}
\hline \multirow{2}{*}{$\begin{array}{l}\text { Subgroup } \\
\text { Bandwidth }\end{array}$} & \multicolumn{4}{|c|}{ Girls } & \multicolumn{4}{|c|}{ Boys without female siblings } & \multicolumn{4}{|c|}{ Boys with female siblings } \\
\hline & 100 & 250 & 500 & Mean & 100 & 250 & 500 & Mean & 100 & 250 & 500 & Mean \\
\hline & $(1)$ & $(2)$ & (3) & $(4)$ & $(5)$ & $(6)$ & $(7)$ & $(8)$ & $(9)$ & $(10)$ & $(11)$ & $(12)$ \\
\hline Economic activities for someone who is not a member of the & -0.024 & 0.023 & 0.012 & 0.052 & 0.020 & 0.026 & 0.001 & 0.075 & -0.031 & 0.020 & 0.012 & 0.051 \\
\hline household (7 days prior to the interview). & $(0.031)$ & $(0.026)$ & $(0.020)$ & & $(0.043)$ & $(0.038)$ & $(0.033)$ & & $(0.030)$ & $(0.025)$ & $(0.019)$ & \\
\hline CVC & 0.0335 & 0.0445 & 0.0413 & & 0.0545 & 0.0641 & 0.0599 & & 0.0381 & 0.0425 & 0.0404 & \\
\hline Hours in economic activities for someone who is not a member & -3.056 & -0.397 & 0.204 & 5.234 & 3.948 & -0.316 & 0.591 & 6.461 & 2.349 & -0.112 & 0.018 & 6.564 \\
\hline of the household (7 days prior to the interview). & $(2.422)$ & $(0.968)$ & $(1.001)$ & & $(3.108)$ & $(1.340)$ & $(1.195)$ & & $(1.478)$ & $(1.142)$ & $(0.964)$ & \\
\hline CVC & 5.9773 & 7.9055 & 8.0269 & & 6.7110 & 10.4493 & 10.3251 & & 9.4535 & 10.8877 & 10.4986 & \\
\hline Participation in economic activities or chores for the household & -0.002 & 0.017 & 0.049 & 0.775 & 0.070 & $0.084^{*}$ & $0.146 * * *$ & 0.695 & 0.057 & 0.030 & $0.071^{*}$ & 0.725 \\
\hline (7 days prior to the interview). & $(0.062)$ & $(0.039)$ & $(0.031)$ & & $(0.064)$ & $(0.048)$ & $(0.039)$ & & $(0.067)$ & $(0.040)$ & $(0.038)$ & \\
\hline CVC & 0.1406 & 0.1378 & 0.1365 & & 0.1539 & 0.1552 & 0.1601 & & 0.1601 & 0.1605 & 0.1606 & \\
\hline Number of economic activities and choresconducted for the & -0.231 & -0.124 & -0.022 & 2.820 & 0.165 & 0.193 & 0.233 & 2.100 & 0.027 & -0.255 & -0.067 & 2.268 \\
\hline household (7 days prior to the interview). & $(0.288)$ & $(0.196)$ & $(0.166)$ & & $(0.403)$ & $(0.231)$ & $(0.202)$ & & $(0.343)$ & $(0.236)$ & $(0.206)$ & \\
\hline CVC & 3.1104 & 3.2746 & 3.2969 & & 2.8283 & 2.9535 & 2.9649 & & 3.1894 & 3.3151 & 3.3599 & \\
\hline Remunerated economic activities for someone who is not a & $0.005^{*}$ & $0.007^{*}$ & 0.003 & 0.006 & -0.001 & 0.005 & -0.000 & 0.010 & -0.016 & -0.001 & -0.001 & 0.006 \\
\hline member of the household (7 days prior to the interview). & $(0.003)$ & $(0.004)$ & $(0.003)$ & & $(0.008)$ & $(0.009)$ & $(0.008)$ & & $(0.014)$ & $(0.006)$ & $(0.005)$ & \\
\hline CVC & 0.0022 & 0.0057 & 0.0053 & & 0.0059 & 0.0106 & 0.0091 & & 0.0054 & 0.0064 & 0.0058 & \\
\hline Economic activities for someone who is not a member of the & $-0.112 * *$ & 0.026 & -0.014 & 0.087 & 0.007 & 0.057 & 0.019 & 0.100 & $-0.149 * * *$ & 0.009 & -0.014 & 0.091 \\
\hline household (year prior to the interview). & $(0.050)$ & $(0.035)$ & $(0.025)$ & & $(0.073)$ & $(0.048)$ & $(0.038)$ & & $(0.057)$ & $(0.041)$ & $(0.029)$ & \\
\hline $\mathrm{CVC}$ & 0.0686 & 0.0766 & 0.0718 & & 0.0755 & 0.0850 & 0.0796 & & 0.0751 & 0.0787 & 0.0745 & \\
\hline Observations: children & 4,453 & 7,491 & 8,611 & 9517 & 1,784 & 2,826 & 3,306 & 3584 & 3,368 & 5,600 & 6,453 & 7188 \\
\hline Observations: children (hours in economic activities) & 181 & 434 & 453 & 488 & 125 & 240 & 258 & 268 & 155 & 311 & 334 & 366 \\
\hline
\end{tabular}

Notes: ${ }^{* * *} \mathrm{p}<0.01, * * \mathrm{p}<0.05,{ }^{*} \mathrm{p}<0.1$. Estimated discontinuities at the threshold scores. All estimates are based on a second order polynomial and include department fixed effects and the variables displayed in

table 2 as controls. Standard errors (in parentheses) are clustered at the village level. Means are calculated for the unrestricted sample of 271 villages. 
Table 7: School attendance (conditional on being enrolled in school)

\begin{tabular}{|c|c|c|c|c|c|c|c|c|c|c|c|c|}
\hline \multirow{2}{*}{$\begin{array}{l}\text { Subgroup } \\
\text { Bandwidth }\end{array}$} & \multicolumn{4}{|c|}{ Girls } & \multicolumn{4}{|c|}{ Boys without female siblings } & \multicolumn{4}{|c|}{ Boys with female siblings } \\
\hline & 100 & 250 & 500 & Mean & 100 & 250 & 500 & Mean & 100 & 250 & 500 & Mean \\
\hline & $(1)$ & $(2)$ & (3) & $(4)$ & $(5)$ & $(6)$ & $(7)$ & $(8)$ & $(9)$ & $(10)$ & $(11)$ & $(12)$ \\
\hline Self reported school attendance on most recent day school & -0.002 & 0.020 & 0.015 & 0.970 & -0.027 & -0.047 & -0.002 & 0.967 & -0.056 & -0.005 & 0.020 & 0.971 \\
\hline was open & $(0.053)$ & $(0.029)$ & $(0.027)$ & & $(0.059)$ & $(0.033)$ & $(0.026)$ & & $(0.044)$ & $(0.024)$ & $(0.027)$ & \\
\hline CVC & 0.0319 & 0.0294 & 0.0273 & & 0.0275 & 0.0270 & 0.0276 & & 0.0233 & 0.0265 & 0.0242 & \\
\hline Teacher reported attendance during 3 days prior to school & -0.091 & -0.083 & -0.051 & 2.937 & 0.086 & 0.045 & -0.028 & 2.929 & 0.001 & -0.032 & -0.037 & 2.940 \\
\hline survey & $(0.130)$ & $(0.059)$ & $(0.048)$ & & $(0.204)$ & $(0.108)$ & $(0.079)$ & & $(0.094)$ & $(0.048)$ & $(0.041)$ & \\
\hline CVC & 0.0801 & 0.0647 & 0.0603 & & 0.0654 & 0.0635 & 0.0659 & & 0.0725 & 0.0617 & 0.0581 & \\
\hline \multirow[t]{2}{*}{ Presence in school during roll-call } & 0.058 & 0.004 & 0.004 & 0.970 & 0.271 & 0.099 & 0.036 & 0.950 & 0.047 & -0.031 & -0.026 & 0.962 \\
\hline & $(0.080)$ & $(0.047)$ & $(0.037)$ & & $(0.221)$ & $(0.112)$ & $(0.079)$ & & $(0.050)$ & $(0.038)$ & $(0.033)$ & \\
\hline CVC & 0.0313 & 0.0285 & 0.0271 & & 0.0542 & 0.0432 & 0.0411 & & 0.0378 & 0.0332 & 0.0315 & \\
\hline Observations: children (self reported school attendance) & 1,739 & 2,877 & 3,313 & 3,738 & 621 & 987 & 1,195 & 1,332 & 1,221 & 2,040 & 2,367 & 2715 \\
\hline Observations: children (teacher reported and roll-call) & 1,631 & 2,620 & 2,974 & 3,311 & 561 & 836 & 986 & 1,084 & 1,127 & 1,843 & 2,121 & 2396 \\
\hline
\end{tabular}

Notes: ${ }^{* *} \mathrm{p}<0.01,{ }^{* *} \mathrm{p}<0.05,{ }^{*} \mathrm{p}<0.1$. Estimated discontinuities at the threshold scores. All estimates are based on a second order polynomial and include department fixed effects and the variables displayed in table 2 as controls. Standard errors (in parentheses) are clustered at the village level. Means are calculated for the unrestricted sample of 271 villages. 
Table 8: Mathematics and French abilities

\begin{tabular}{|c|c|c|c|c|c|c|c|c|c|}
\hline \multirow{2}{*}{$\begin{array}{l}\text { Subgroup } \\
\text { Bandwidth }\end{array}$} & \multicolumn{3}{|c|}{ Girls } & \multicolumn{3}{|c|}{ Boys without female siblings } & \multicolumn{3}{|c|}{ Boys with female siblings } \\
\hline & 100 & 250 & 500 & 100 & 250 & 500 & 100 & 250 & 500 \\
\hline & $(1)$ & $(2)$ & (3) & $(4)$ & (5) & $(6)$ & $(7)$ & $(8)$ & (9) \\
\hline Mathematics test Z-score: in school only. & $\begin{array}{l}-0.118 \\
(0.425)\end{array}$ & $\begin{array}{c}0.365 \\
(0.286)\end{array}$ & $\begin{array}{c}0.505 * * \\
(0.217)\end{array}$ & $\begin{array}{c}0.027 \\
(0.641)\end{array}$ & $\begin{array}{c}0.314 \\
(0.275)\end{array}$ & $\begin{array}{l}0.346^{*} \\
(0.187)\end{array}$ & $\begin{array}{c}0.235 \\
(0.358)\end{array}$ & $\begin{array}{c}0.250 \\
(0.219)\end{array}$ & $\begin{array}{c}0.378 * * \\
(0.161)\end{array}$ \\
\hline Mathematics test Z-score: all other & $\begin{array}{l}-0.064 \\
(0.202)\end{array}$ & $\begin{array}{c}0.303^{* * *} \\
(0.094)\end{array}$ & $\begin{array}{c}0.294^{* * *} \\
(0.079)\end{array}$ & $\begin{array}{c}0.125 \\
(0.163) \\
\end{array}$ & $\begin{array}{c}0.274^{* * *} \\
(0.100)\end{array}$ & $\begin{array}{c}0.332 * * * \\
(0.090)\end{array}$ & $\begin{array}{l}-0.021 \\
(0.168)\end{array}$ & $\begin{array}{c}0.292^{* * *} \\
(0.088)\end{array}$ & $\begin{array}{c}0.288 * * * \\
(0.070)\end{array}$ \\
\hline Chow test: & no diff & no diff & no diff & no diff & no diff & no diff & no diff & no diff & no diff \\
\hline CVC & 0.7089 & 0.6949 & 0.7090 & 0.5628 & 0.5737 & 0.5980 & 0.6664 & 0.6880 & 0.6942 \\
\hline French test Z-score: in school only. & $\begin{array}{l}-0.398 \\
(0.285)\end{array}$ & $\begin{array}{c}0.362 \\
(0.245)\end{array}$ & $\begin{array}{c}0.406^{*} \\
(0.216)\end{array}$ & $\begin{array}{c}0.022 \\
(0.480)\end{array}$ & $\begin{array}{c}0.758 * * \\
(0.297)\end{array}$ & $\begin{array}{c}0.224 \\
(0.229)\end{array}$ & $\begin{array}{l}-0.185 \\
(0.345)\end{array}$ & $\begin{array}{c}0.228 \\
(0.204)\end{array}$ & $\begin{array}{c}0.333^{* *} \\
(0.153)\end{array}$ \\
\hline French test Z-score: all other & $\begin{array}{c}0.053 \\
(0.154)\end{array}$ & $\begin{array}{c}0.265^{* * *} \\
(0.086)\end{array}$ & $\begin{array}{c}0.266^{* * *} \\
(0.071)\end{array}$ & $\begin{array}{c}0.073 \\
(0.147)\end{array}$ & $\begin{array}{c}0.220^{* *} \\
(0.097)\end{array}$ & $\begin{array}{c}0.245^{* * *} \\
(0.088)\end{array}$ & $\begin{array}{c}0.128 \\
(0.119)\end{array}$ & $\begin{array}{c}0.277^{* * *} \\
(0.086)\end{array}$ & $\begin{array}{c}0.267 * * * \\
(0.069)\end{array}$ \\
\hline Chow test: & no diff & no diff & no diff & no diff & $*$ & no diff & no diff & no diff & no diff \\
\hline $\mathrm{CVC}$ & 0.6695 & 0.6755 & 0.6990 & 0.5344 & 0.5932 & 0.6306 & 0.6507 & 0.6792 & 0.6915 \\
\hline Observations & 4,453 & 7,491 & 8,611 & 1,784 & 2,826 & 3,306 & 3,368 & 5,600 & 6,453 \\
\hline
\end{tabular}

Notes: $* * * \mathrm{p}<0.01, * * \mathrm{p}<0.05, * \mathrm{p}<0.1$. Estimated discontinuities at the threshold scores. All estimates are based on a second order polynomial and

include department fixed effects and the variables displayed in table 2 as controls. CVC and number of observations calculated on the basis of the Chow test regression which contains all fixed effects and controls interacted with a dummy for economic activities and chores. Standard errors (in parentheses) are

clustered at the village level. Means are calculated for the unrestricted sample of 271 villages. 


\section{Figures}

Figure 1: Overall impact on (self-reported) school enrollment

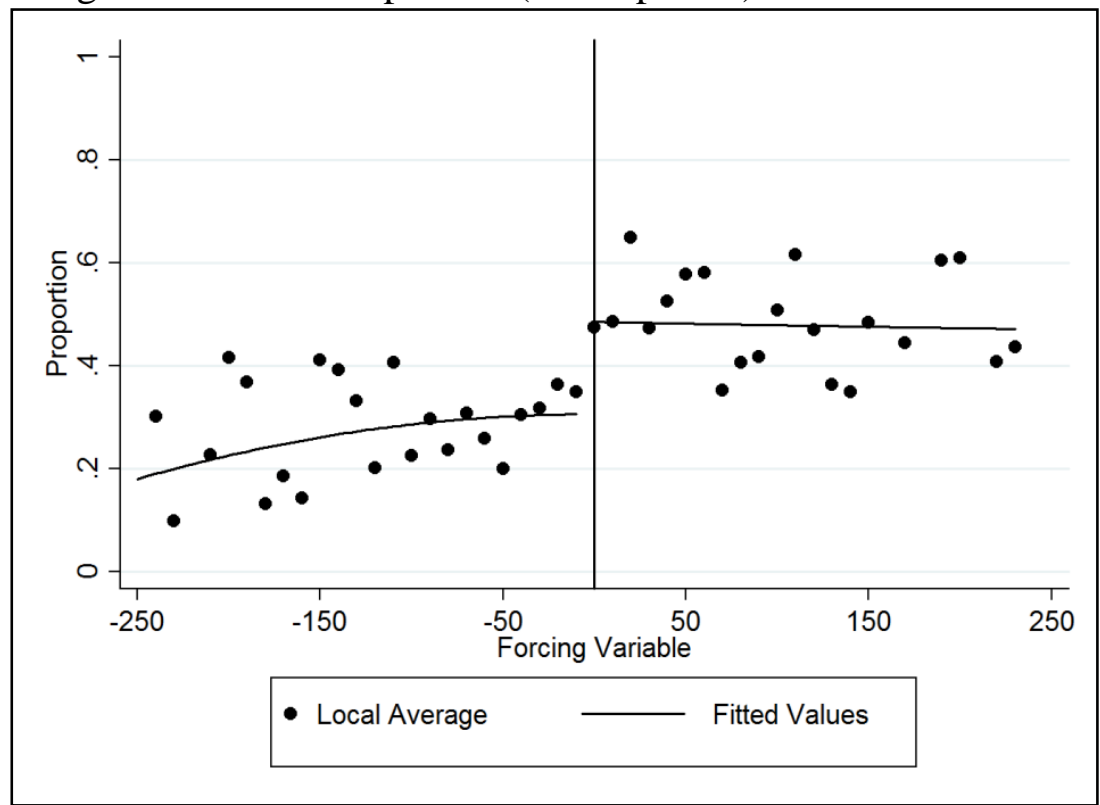

Notes: Proportion of children enrolled in school in the 2007 - 2008 school year as a function of the BRIGHT program forcing variable. Dots represent local averages at a bin size of 10 and the lines represent quadratically fitted regressions, all corrected for department fixed effects.

Figure 2: Overall impact on economic activities and chores

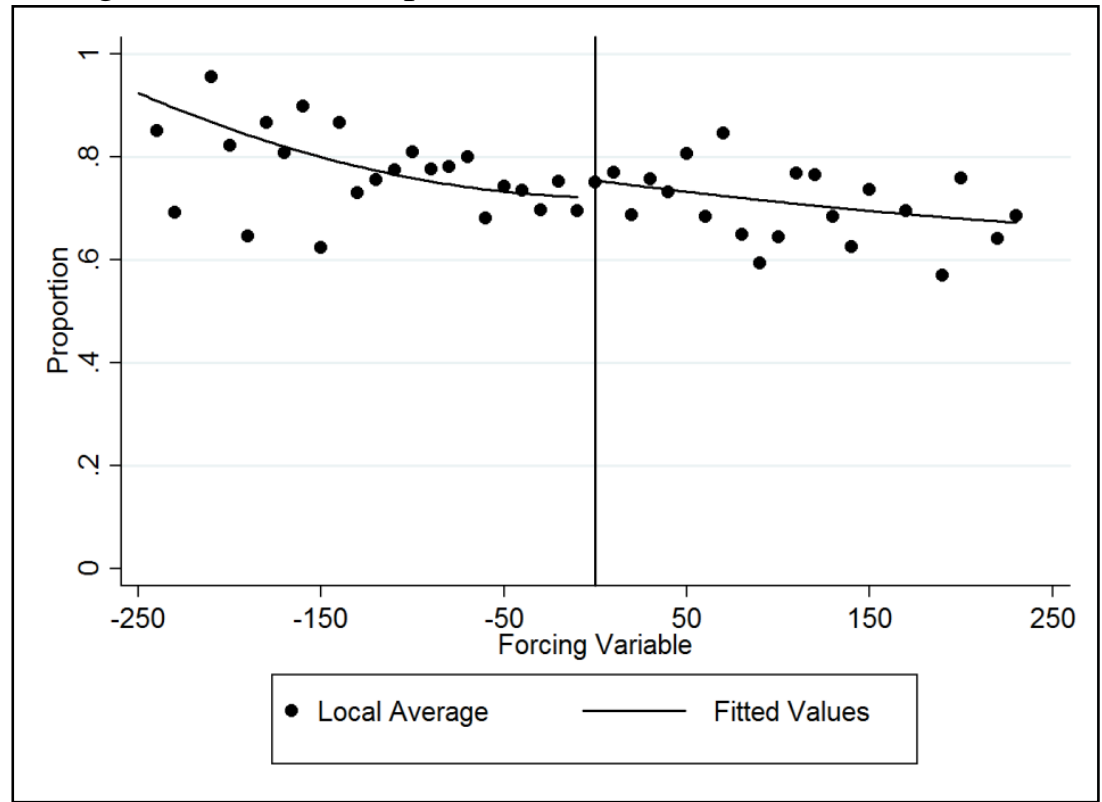

Notes: Proportion of children engaged in economic activities or chores in the 7 days prior to the interview as a function of the BRIGHT program forcing variable. Dots represent local averages at a bin size of 10 and the lines represent quadratically fitted regressions, all corrected for department fixed effects. 
Figure 3: Disaggregated impact on (self-reported) school enrollment and participation in economic activities and chores

Panel A: Girls
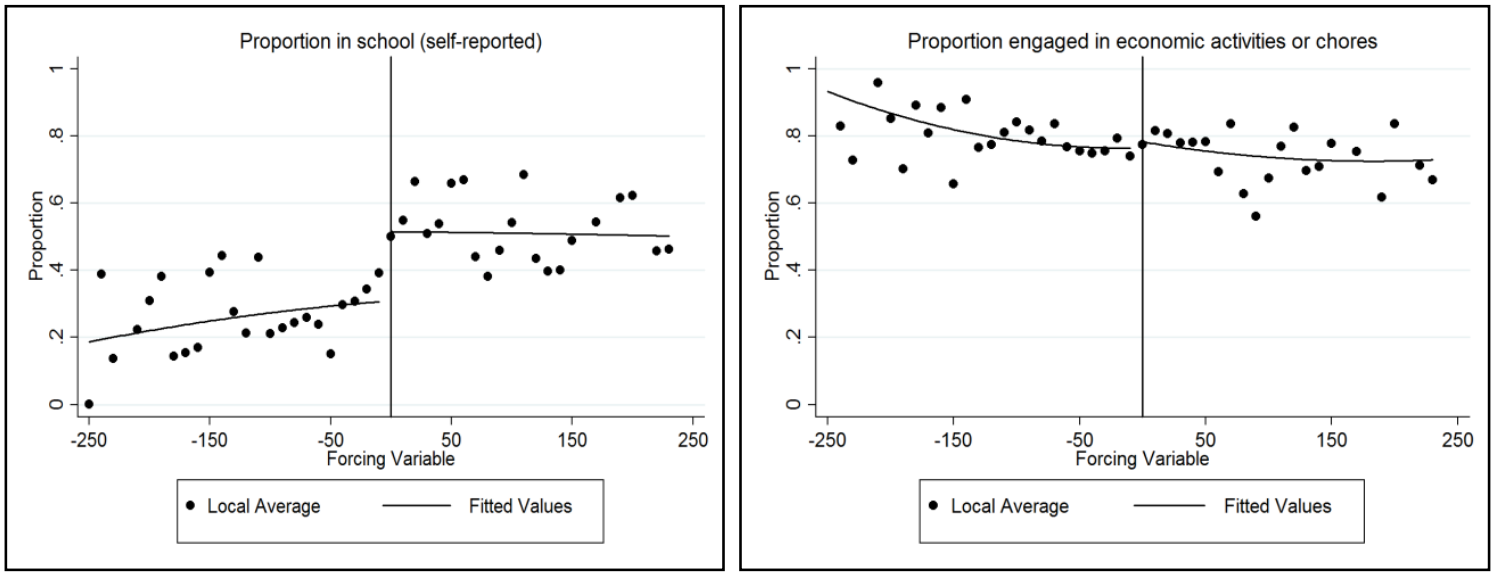

Panel B: Boys without female siblings
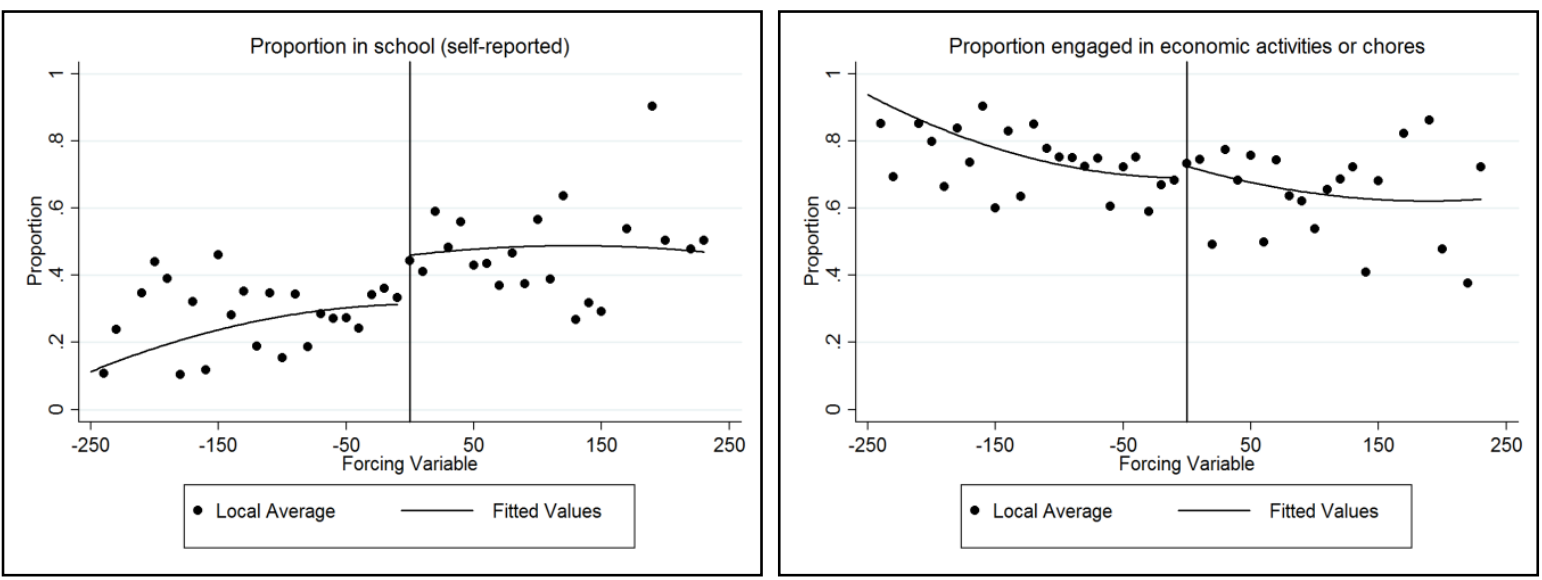

Panel C: Boys with female siblings
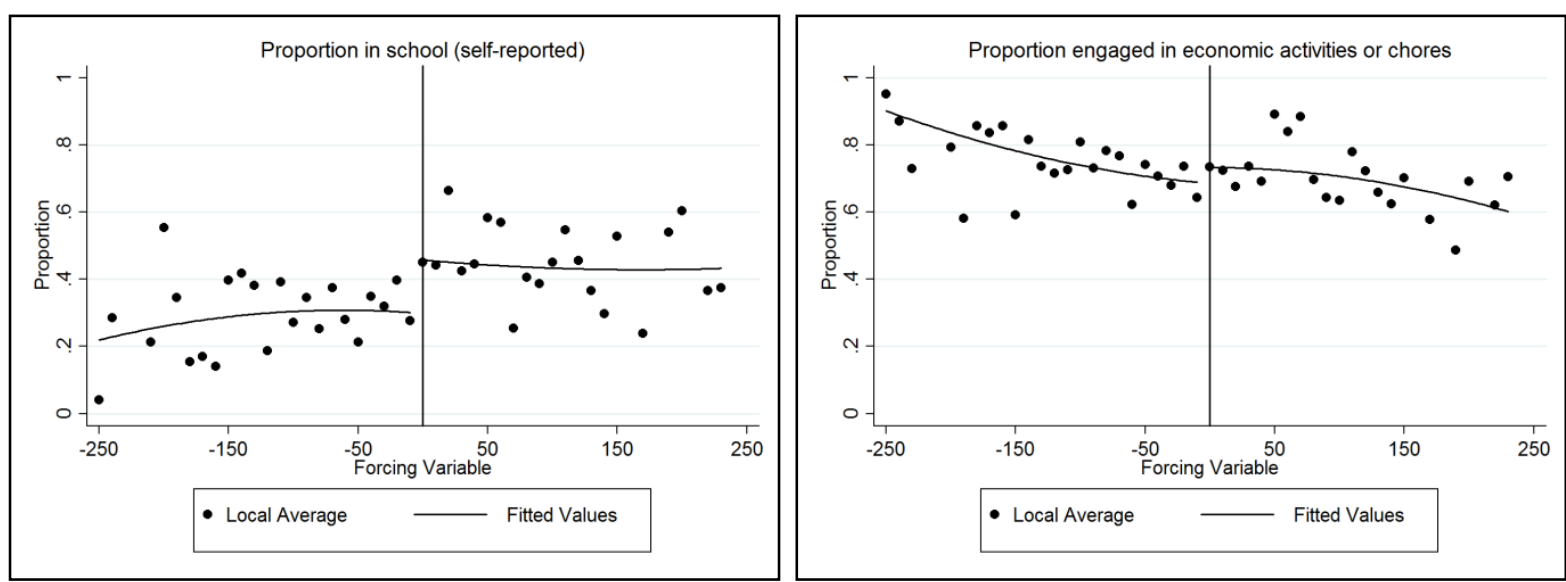

Notes: Proportion of children enrolled in school and the proportion engaged in economic activities or chores in the 7 days prior to the interview as a function of the BRIGHT program forcing variable. Dots represent local averages at a bin size of 10 and the lines represent quadratically fitted regressions, all corrected for department fixed effects. 